\title{
Radiation and Health Technology Laboratory Capabilities
}

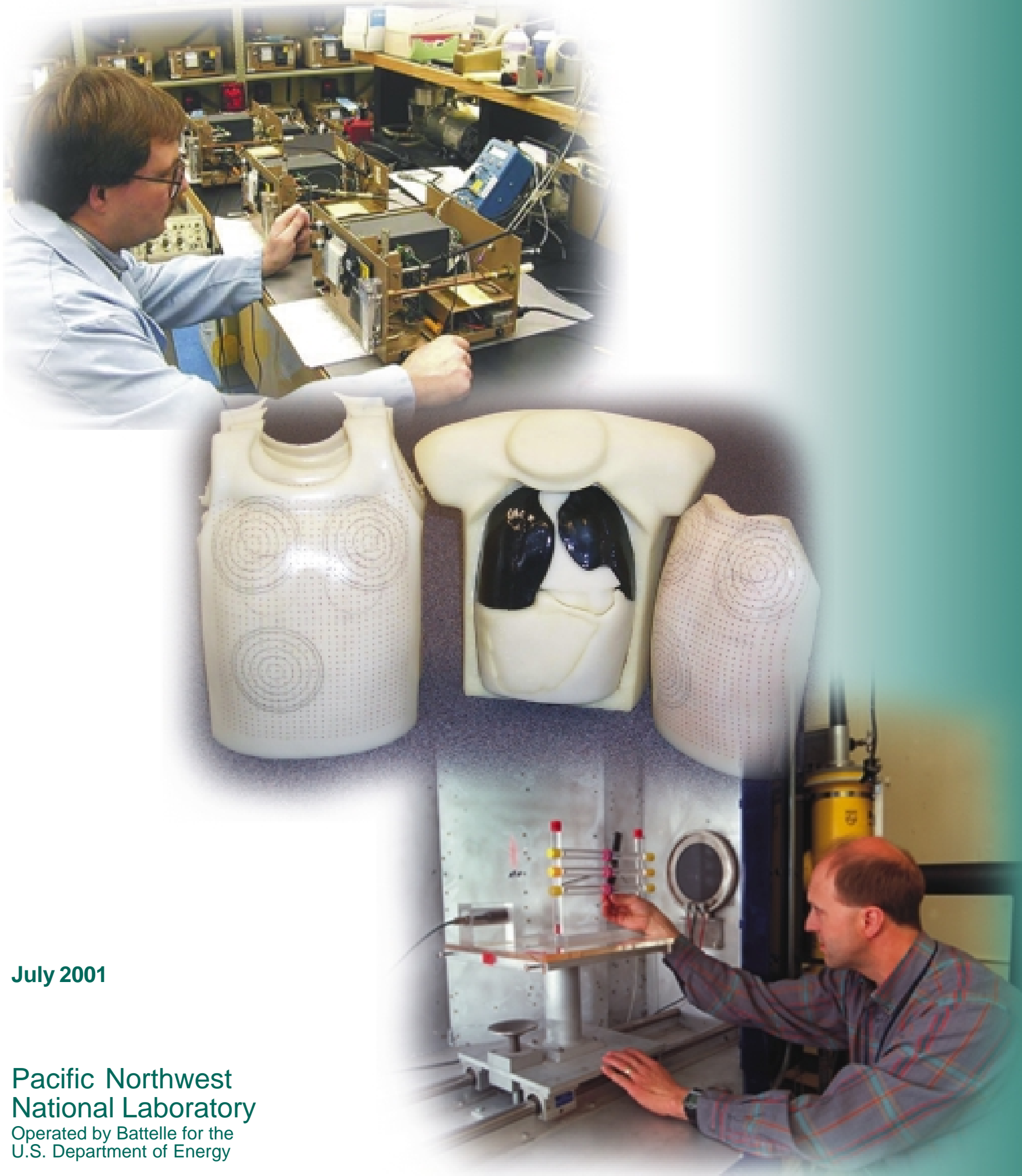




\title{
DISCLAIMER
}

This report was prepared as an account of work sponsored by an agency of the United States Government. Neither the United States Government nor any agency thereof, nor Battelle Memorial Institute, nor any of their employees, makes any warranty, express or implied, or assumes any legal liability or responsibility for the accuracy, completeness, or usefulness of any information, apparatus, product, or process disclosed, or represents that its use would not infringe privately owned rights. Reference herein to any specific commercial product, process, or service by trade name, trademark, manufacturer, or otherwise does not necessarily constitute or imply its endorsement, recommendation, or favoring by the United States Government or any agency thereof, or Battelle Memorial Institute. The views and opinions of authors expressed herein do not necessarily state or reflect those of the United States Government or any agency thereof.

\author{
PACIFIC NORTHWEST NATIONAL LABORATORY \\ operated by \\ BATTELLE \\ for the \\ UNITED STATES DEPARTMENT OF ENERGY \\ under Contract DE-ACO6-76RL0183O
}

\section{On the Cover}

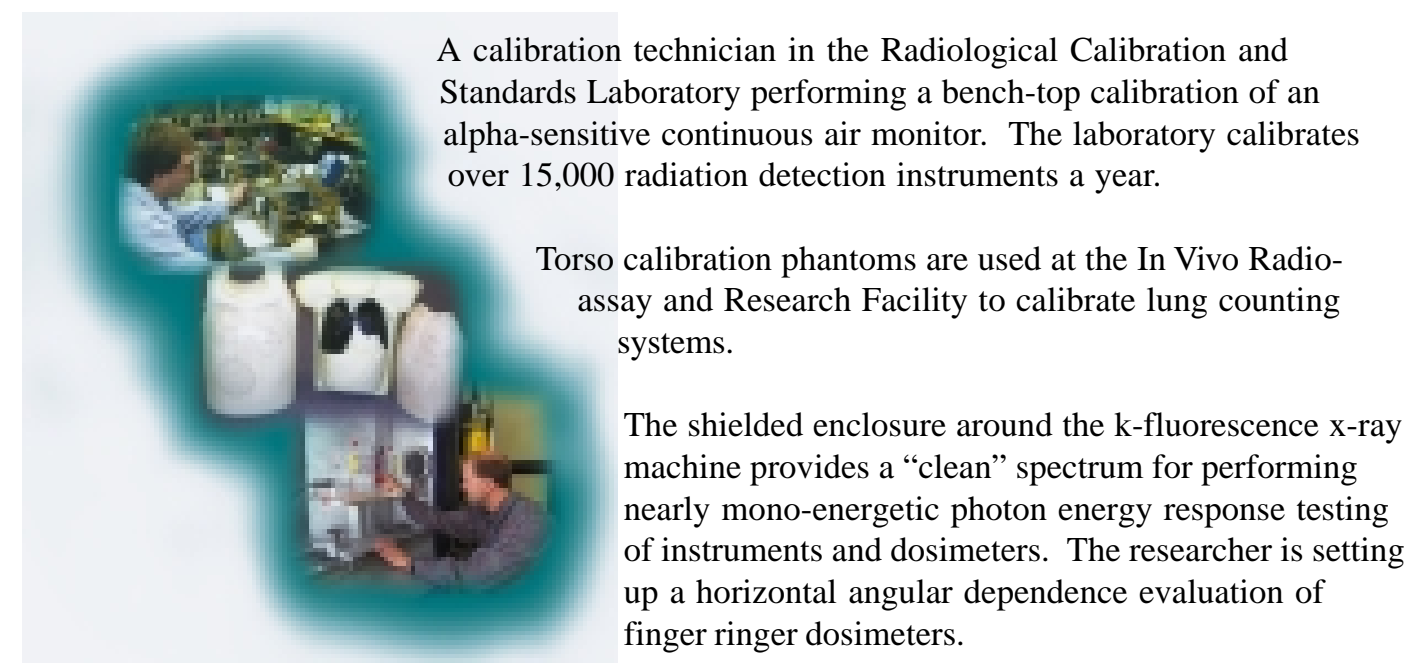

This document is intended to serve as a reference guide for PNNL staff and clients who desire technical information about the broad capabilities of the Radiation and Health Technology Laboratories. The document has been expanded and revised several times to add additional information as requested by its users. We welcome comments and suggestions for future revisions. Please contact Mark Hevland at 509-376-4014 or the calibration laboratory via e-mail at calibration@pnl.gov. 


\section{Radiation and Health Technology Laboratory Capabilities}

R.W. Goles

M.L. Johnson

R.K. Piper

J.D. Peters

July 2001

Prepared for

the U.S. Department of Energy

under Contract DE-AC06-76RLO 1830

Pacific Northwest National Laboratory

Richland, Washington 99352

\author{
M.K. Murphy \\ M.S. Mercado \\ D.E. Bihl \\ T.P. Lynch
}




\section{Summary}

The Radiological Standards and Calibration Laboratory (RS\&CL) at Pacific Northwest National Laboratory (PNNL) provides a broad mix of calibration and testing services within a single organization. Its staff of over 50 individuals includes several nationally recognized leaders in the fields of dosimetry, performance testing, and radiological calibrations. The laboratory provides a unique mix of radiological and environmental testing and characterization facilities that give clients access to a broader variety of test capabilities than is typically available within a single laboratory. The organization performs instrument, radiological source, and dosimetry calibrations; maintains the reference standards necessary to trace the Hanford Site programs and other research- and quality-related programs to national standards; performs environmental effects testing on equipment and materials; performs non-destructive assay for special nuclear material; and performs in vivo assay of radioactive materials. This document describes the facilities and procedures used to accomplish this mission.

The specialized facilities developed to support calibrations, dosimetry, in vivo bioassay, and instrument performance evaluations include the following:

$\checkmark$ a low-scatter room that provides neutron (heavy water- $\left[\mathrm{D}_{2} 0-\right]$ moderated and unmoderated $\left.{ }^{252} \mathrm{Cf}\right)$ and gamma $\left({ }^{60} \mathrm{Co}\right.$ and $\left.{ }^{137} \mathrm{Cs}\right)$ irradiations in a free-space geometry

$\checkmark$ a source well room equipped with four calibration source wells (3 gamma and 1 neutron) designed to expedite routine instrument calibrations

$\checkmark$ a photon laboratory capable of National Institute of Technology (NIST) and International Standards Organization (ISO) specified bremsstrahlung and K-fluorescent x-ray spectra, and gamma reference fields using an open $(2 \pi)$ ${ }^{241} \mathrm{Am}$ source and a collimated beam ${ }^{137} \mathrm{Cs}$ irradiator

$\checkmark$ a high-exposure facility capable of delivering a large-volume, uniform gamma radiation field $\left(0.08 \mathrm{R} / \mathrm{h}\right.$ to $\left.\sim 5 \times 10^{4} \mathrm{R} / \mathrm{h}\right)$ for standard calibrations or evaluating the effects of radiological dose on materials

a beta-particle laboratory that maintains ${ }^{85} \mathrm{Kr},{ }^{204} \mathrm{Tl},{ }^{147} \mathrm{Pm}$, and ${ }^{90} \mathrm{Sr} /{ }^{90} \mathrm{Y}$ as international secondary standard sources for instrument and dosimetry characterization

$\checkmark$ an instrument calibration laboratory that provides the flexibility required to calibrate a wide range of portable and semiportable measurement and test equipment, radiological instrumentation, and radioactive sources

an environmental effects laboratory for evaluating the response of materials and equipment to environmental influences (including evaluating the performance of health physics instruments against American National Standards Institute (ANSI) and other performance standards 
$\checkmark$ the U.S. Department of Energy (DOE) accredited thermoluminescent dosimetry laboratories that directly support the Hanford Site personnel, environmental, and nuclear accident dosimetry programs

$\checkmark$ high-intensity irradiators, including a high-level ${ }^{60} \mathrm{Co}$ irradiator that support specialized or high-dose studies

$\checkmark$ an in vivo bioassay facility equipped with six counting systems for measuring low levels of radioactive materials in the human body

a Non-Destructive Analysis (NDA) Laboratory that is capable of performing measurements on a variety of waste containers including 55-gallon drums, assorted boxes and casks, and measurements of onsite/offsite radiological sources (e.g., hold-up mesaurements in facilities, emerging monitoring in the field).

PNNL, in support of the Hanford Site's RS\&CL, has been accredited as a Calibration Laboratory for ionizing radiation through the National Voluntary Laboratory Accreditation Program (NVLAP). This accreditation implies NIST concurrence that PNNL provides highly accurate instrument calibrations and dosimeter irradiations and that the RS\&CL complies with the technical requirements of NIST Special Publication 812 and the ISO and ANSI quality and administrative requirements as interpreted by the NVLAP Handbook 150. Similarly, DOE has also accredited PNNL's Dosimetry Program since the inception of DOE's Laboratory Accreditation Program (DOELAP) in 1989. 


\section{Contents}

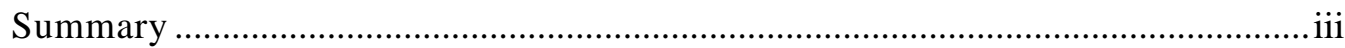

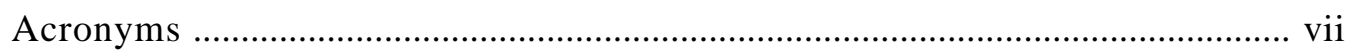

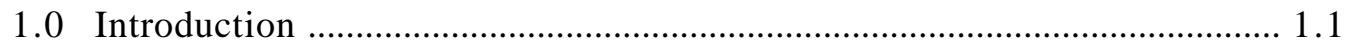

2.0 Radiation Standards and Calibration Laboratory Capabilities ..................... 2.1

2.1 Calibration Laboratory Layout …....................................................... 2. 2.1

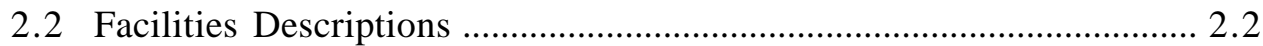

2.2.1 Low-Scatter Room.............................................................. 2.2

2.2.2 Source Well Room................................................................... 2.4

2.2.3 X-Ray Facilities and Capabilities ......................................... 2.5

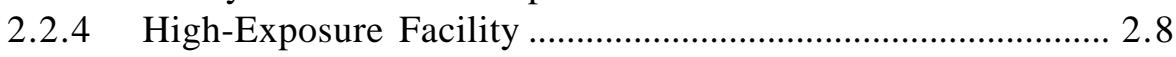

2.2.5 Beta Standards Laboratory …………................................... 2.10

2.2.6 Radiological Calibration Laboratories ................................... 2.10

2.2.7 Measuring and Test Equipment Calibration Laboratory ...... 2.11

2.2.8 Environmental Effects Laboratory ......................................... 2.11

2.2.9 Instrument Repair Shop ......................................................... 2.14

2.2.10 Thermoluminescence Dosimetry Laboratory ….................... 2.15

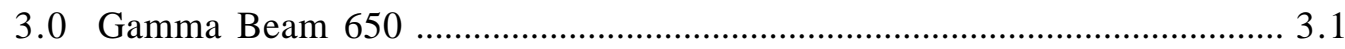

4.0 Non-Destructive Analysis Laboratory ….................................................. 4.1

5.0 In Vivo Radioassay and Research Facility ................................................ 5.1

5.1 In Vivo Counting Facilities ................................................................ 5.1

5.2 Calibration Phantoms ....................................................................... 5.3

6.0 Laboratory Standards and Traceability Program ........................................ 6.1

6.1 Quality Assurance Program .............................................................. 6.1

6.2 Local Standards and Traceability Program ........................................ 6.2

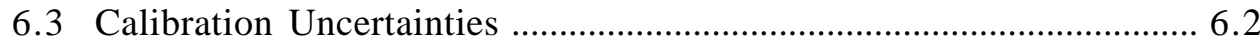

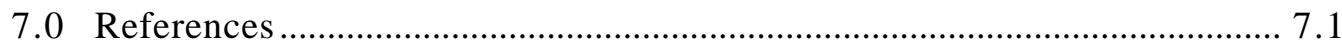

\section{Figures}

2.1 Radiological Standards and Calibration Laboratory …............................... 2.1

2.2 Instrument verification in the instrument and/or

Sealed Source Receiving Room ............................................................ 2.2

2.3 Instrument and Sealed Source Receiving Room ........................................ 2.2

2.4 The Laboratory's Low-Scatter Room ........................................................ 2.3

2.5 The Low-Scatter Room Tower Irradiation Position...................................... 2. 2.3

2.6 Floor-Level Station in the Low-Scatter Room ............................................. 2.4

2.7 Well Room with Three ${ }^{137} \mathrm{Cs}$ Wells and One ${ }^{252} \mathrm{Cf}$ Well .............................. 2.. 2.5 


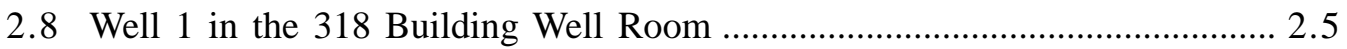

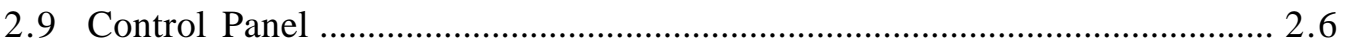

2.10 Two Philips Model 324 X-Ray Units .......................................................... 2.6

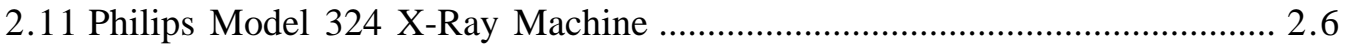

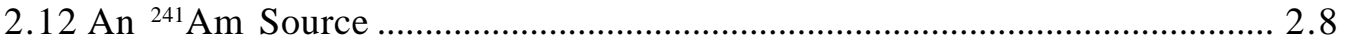

2.13 The J.L. Shepherd Model 81, 100-Ci ${ }^{137} \mathrm{Cs}$ Irradiator ................................ 2.9

2.14 The High-Exposure Facility ........................................................................ 2.9

2.15 The High-Exposure Facility Control Room ............................................. 2.10

2.16 A Buchler-Amersham Irradiation Jig and Point Source Inventory

are the Basis for PNNL's Beta Irradiations ................................................ 2.10

2.17 Environmental Chamber ........................................................................ 2.12

2.18 Pressure/Vacuum Chamber for Simulating Variations in Ambient Pressure Levels ..................................................................... 2.12

2.19 High-Frequency, High-Acceleration Vibration Table .............................. 2.13

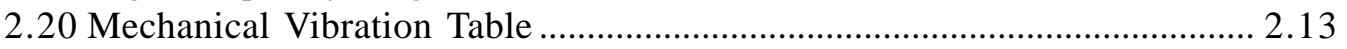

2.21 Mechanical Shock Testing Apparatus ..................................................... 2.14

2.22 Parallel-Plate Radio Frequency Exposure System and Transverse Electromagnetic Cell ................................................... 2.14

2.23 Magnetic Field Exposure System .............................................................. 2...14

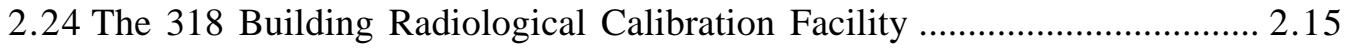

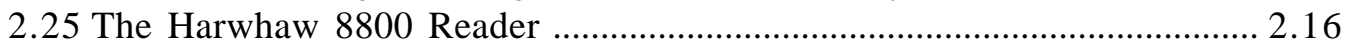

2.26 Harshaw 6600 Reader for Finger Rings ….................................................. 2.16

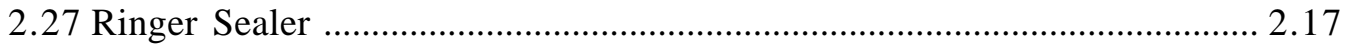

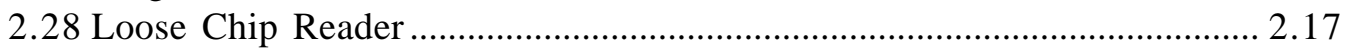

2.29 Track-Etch Dosimeter (TED) Reader ....................................................... 2.17

3.1 The Gamma Beam 650 ............................................................................... 3.1

3.2 A Close Up of the 12 Source Tubes in the Gamma Beam 650 ................... 3.1

4.1 Segmented Gamma-Scan Neturon Assay System ...................................... 4.1

4.2 Mobile Non-Destructive Assay Laboratory .............................................. 4.1

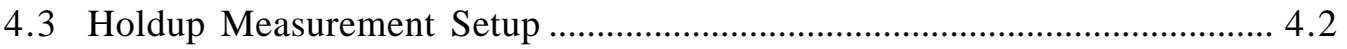

5.1 Coaxial High-Purity Germanium Detectors in Palmer Room ……............. 5.2

5.2 Standup Counter Detectors ................................................................... 5.2

5.3 Iron Room Counting System ................................................................... 5.3

5.4 Stainless Steel Room Counting System ................................................... 5.3

5.5 Torso Calibration Phantom ............................................................................ 5.4

5.6 Bottle Manikin Absorption Phantom .......................................................... 5.4

\section{Tables}

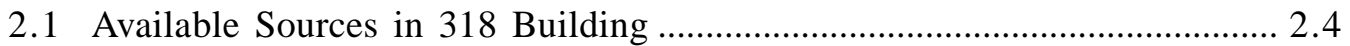

2.2 Available NIST-Specified Bremsstrahlung X-Ray Reference Fields ........... 2. 2.7

2.3 Available ISO-Specified Bremsstrahlung X-Ray Reference Fields -

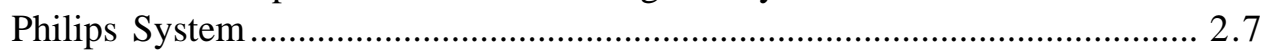

2.4 Available K-Fluorscence Reference X-Ray Fields ................................... 2.8

2.5 Available Beta Reference Fields ........................................................... 2.10

5.1 Typical Minimum Detectable Activities (MDA) ........................................ 5.1 


\section{Acronyms}

ANSI American National Standards Institute

BOMAB bottle manikin absorption (phantom)

CFR Code of Federal Regulations

CLIR Calibration Laboratory for Ionizing Radiation

CR\&A Calibration Research and Accreditation (group)

DOE U.S. Department of Energy

DOELAP Department of Energy Laboratory Accreditation Program

EM electromagnetic

FWHM full width, half maximum

HEPA high-efficiency particulate air (filter)

HPGe high-purity germanium (detector)

IAEA International Atomic Energy Agency

ISO International Standards Organization

IVMP In Vivo Monitoring Program

IVRRF In Vivo Radioassay and Research Facility

JAERI Japan Atomic Energy Research Institute

MQA measurement quality assurance

M\&TE measuring and test equipment

NDA non-destructive analysis

NIST National Institute of Standards and Technology

NRPB National Radiation Protection Board

NVLAP National Voluntary Laboratory Accreditation Program

PNNL Pacific Northwest National Laboratory

PTB Physikalisch-Technische Bundesanstalt

QA quality assurance

$\mathrm{RF} \quad$ radio frequency

$\mathrm{RH} \quad$ relative humidity

R\&HT Radiation and Health Technology

RS\&CL Radiological Standards and Calibration Laboratory

TED track-etch dosimeter

TLD thermoluminescent dosimeter

TRU transuranic 


\subsection{Introduction}

Radiation and Health Technology (R\&HT), a part of Pacific Northwest National Laboratory (PNNL), (a) performs a variety of services, including calibrations, dosimetry processing, non-destructive analysis, and environmental effects testing. The organization manages several major facilities including the Radiation Standards and Calibration Laboratory and the In Vivo Radioassay and Research Facility (IVRRF). The laboratories support 1) U.S. Department of Energy (DOE) programs at the Hanford Site in south-central Washington State and at other DOE and commercial nuclear sites, 2) programs sponsored by DOE Headquarters and other federal agencies, and 3) research and characterization programs sponsored through the commercial sector.

R\&HT occupies several facilities including the 318 and 331 Building in the Hanford Site's 300 Area, north of the City of Richland; and the 747A Building located in downtown Richland. The 318 Building contains five major exposure rooms and several laboratories used for exposure work preparation, low-activity instrument calibrations, instrument performance evaluations, instrument maintenance, instrument design and fabrication work, thermoluminescent and radiochromic dosimetry, and calibration of measuring and test equipment (M\&TE). The major exposure facilities are a low-scatter room used for neutron and photon exposures, a source well room used for high-volume radiological calibration work, an x-ray facility used for energy response studies, a highexposure facility used for high-rate photon calibration work and radiation hardness tests, a beta standards laboratory used for beta energy response studies and beta reference calibrations, and M\&TE calibration laboratories. Calibrations are routinely performed for personnel dosimeters; health physics instrumentation; photon and neutron transfer standards; alpha, beta, and gamma field sources; and a wide variety of M\&TE.

The 331 building houses the Gamma $650{ }^{60} \mathrm{Co}$ irradiator which is used for high dose studies. The 747A Building located in downtown Richland houses the IVRRF. The facility contains five heavily shielded counting rooms; the iron room, the Palmer room, the stainless steel room, and two lead-shielded rooms. These facilities are used to perform in vivo measurements of radioactive materials in the human body. Several of the rooms are equipped with specialized detectors for measuring radioactive materials such as low-level photons in the lungs or radioiodine in the thyroid.

This document describes R\&HT's facilities and capabilities. It is intended to be used as a reference guide by PNNL staff and clients who require information on the wide range of radiological, environmental, and evaluation laboratory capabilities provided by the R\&HT.

(a) Pacific Northwest National Laboratory is operated for the U.S. Department of Energy by Battelle Memorial Institute under Contract DE-AC06-76RLO 1830. 


\subsection{Radiation Standards and Calibration Laboratory Capabilities}

The laboratory capabilities, and staff who manage these capabilities, are largely located within the 318 Building. The building was selected for the RS\&CL because it contains a large, shielded reactor containment room that was converted to the low-scatter irradiation facility. Other facilities, described in the following sections, were added as projects grew in scope and volume.

The 318 Building contains an unusually robust and varied range of technical capabilities from routine radiological calibration facilities to state-of-the-art photon energy response testing facilities.

\subsection{Calibration Laboratory Layout}

The calibration and testing laboratories are located in the 318 Building, and the adjoining trailer complex. The 318 Building (Figure 2.1), originally a test reactor facility, was converted to the RS\&CL in 1984. Its upper containment room,

having concrete surfaces with inner dimensions of 10-m x 17-m x 9-m high, (33-ft x 55-ft x 30-ft), was converted into a low-scatter facility. The lower containment area was partitioned into a high-exposure rate facility and an x-ray facility. The basement also contains a source storage vault and a neutron source in a heavy-water moderation tank. On the ground floor outside the low-scatter facility are the beta standards laboratory and the M\&TE calibration laboratory.

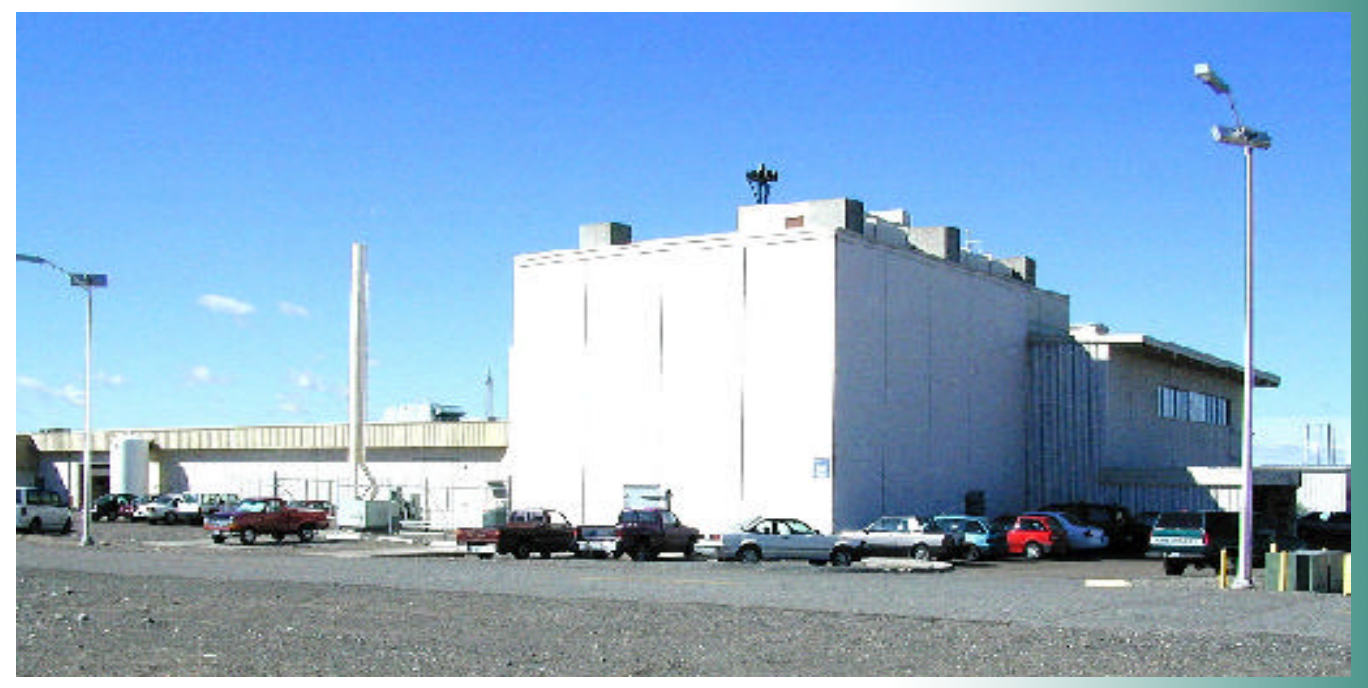

Figure 2.1. Radiological Standards and Calibration Laboratory. Original reactor and associated office building (foreground) and; Phase I and Phase III, south-wing building additions (to left).

The south wing, which was constructed and expanded several times to accommodate increased demands for site calibration and dosimetry services, contains the source well room; instrument and sealed source evaluation, calibration, and testing laboratories; dosimeter preparation and analysis laboratories; and instrument and dosimeter receiving rooms. An instrument repair shop is housed in a trailer that is permanently connected to the building's south wing. 
Instruments and/or sealed sources used on the Hanford Site are routinely delivered to the laboratory's receiving room where they are logged in (Figures 2.2 and 2.3). Following check-in, instruments are either routed to the repair shop or to either the source well room or appropriate calibration laboratory, depending on the state of the instrument and its purpose. Sealed radiation sources are routed directly to the Source Laboratory, which provides low-level alpha-, beta-, and gamma-source calibration services.

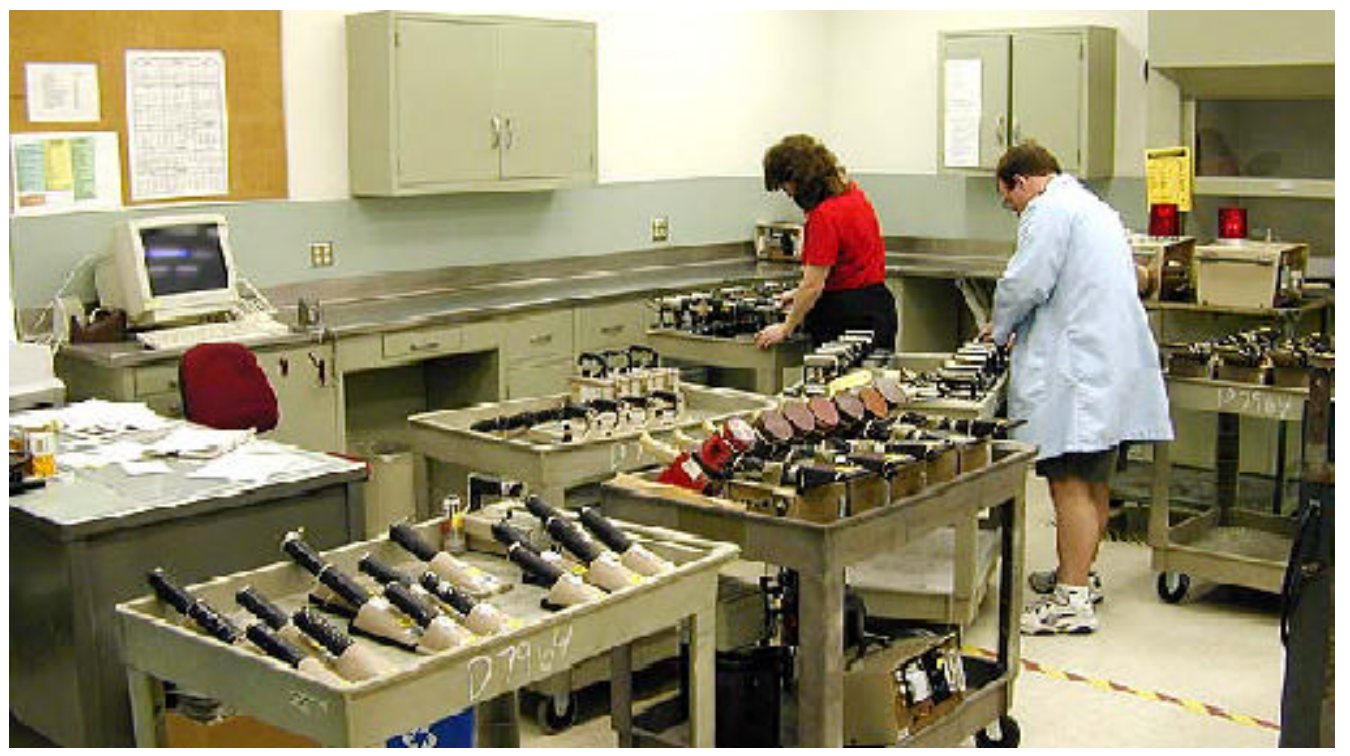

Figure 2.2. Instrument verification in the instrument and/or Sealed Source Receiving Room. Technicians are verifying that instruments are operational prior to leaving the facility for the DOE's Hanford customers. This quick quality check verifies that no last-minute equipment problems exist.

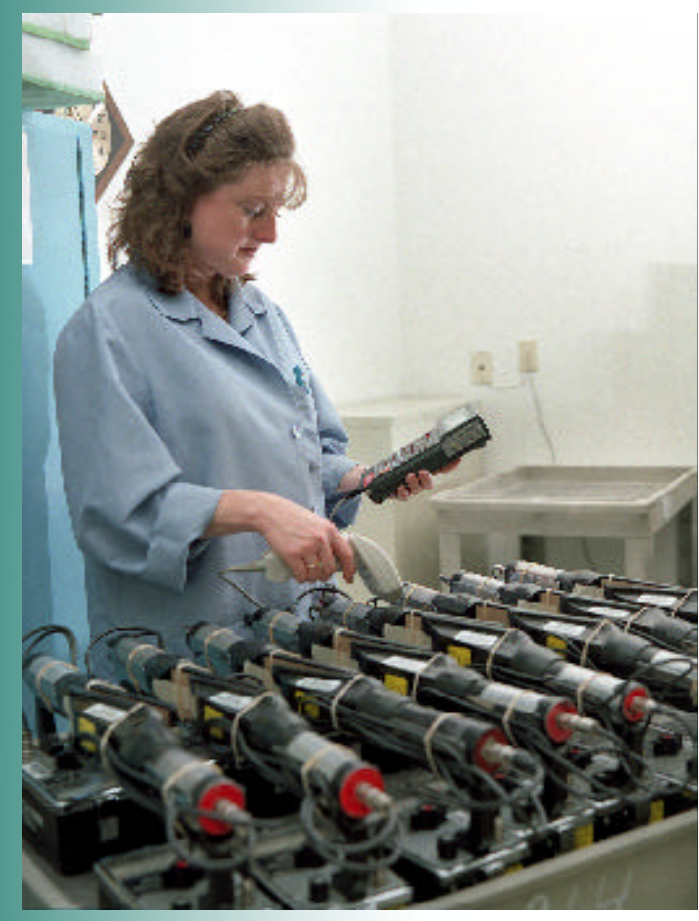

Figure 2.3. Instrument and Sealed Source Receiving Room. All delivered items are logged into the calibration facility database.
The instrument evaluation laboratory is used to evaluate the performance of new instrumentation arriving at the Hanford Site and to develop and test instrumentation for specialized purposes. The testing laboratory, on the other hand, is used to performance test health physics instruments to applicable American National Standards Institute (ANSI) and other performance testing standards.

The dosimetry laboratories are used to provide external dose-ofrecord information for Hanford personnel as required by 10 CFR 835. These laboratories also support Hanford- and offsite-sponsored dosimeter development programs and environmental field measurement capabilities.

\subsection{Facilities Descriptions}

Facilities that comprise the RS\&CL are described in the following sections.

\subsubsection{Low-Scatter Room}

The low-scatter room (shown in Figure 2.4) is a large irradiation area with a relatively low and easily quantified albedo for the 
neutron calibration station housed within it. The room has concrete walls and measures approximately $10 \mathrm{~m} \times 9$ $\mathrm{m} \times 15 \mathrm{~m}$ (33 ft x $30 \mathrm{ft} \times 49 \mathrm{ft})$ in size. The neutron source irradiation station is mounted on a raised aluminum platform located approximately at the geometrical center of the room (Figure 2.5). Another irradiation station is located at the floor level (Figure 2.6).

A pneumatically driven "rabbit" system is used to move sources from their storage locations to any of the irradiation stations. A control console allows the operator to select the source and position along with the irradiation duration. The control system indicates the position of the source (either in storage or at a station) and will also automatically return the source to storage and shut down the system in case of a malfunction in the safety system.

The functional capabilities of each of the irradiation stations within the low-scatter room are described below for the ${ }^{252} \mathrm{Cf},{ }^{60} \mathrm{Co}$, and ${ }^{137} \mathrm{Cs}$ sources available within the pneumatic system and for additional sources that may be configured manually within the facility. Table 2.1 includes additional information on the source geometries and available exposure rates.

- The elevated neutron station is used for $\mathrm{D}_{2} 0$-moderated ${ }^{252} \mathrm{Cf}$ irradiations as specified by various DOE, American, and International Standards (DOE 1986, ANSI 1993, ANSI 1989 a and b, et.al.). Bare ${ }^{252} \mathrm{Cf}$ irradiations specified in some of these standards are also carried out at this station by removing the $\mathrm{D}_{2} 0$ moderator sphere.

The floor-level station is used for bare ${ }^{252} \mathrm{Cf},{ }^{60} \mathrm{Co}$, and ${ }^{137} \mathrm{Cs}$ irradiations. The station has a ring-shaped table constructed of low-density foam to minimize scatter. This table supports pencil and thermoluminescent dosimeters at distances of 50 and $100 \mathrm{~cm}$ from the source. The ring design enables the simultaneous irradiation of many dosimeters to a single source.

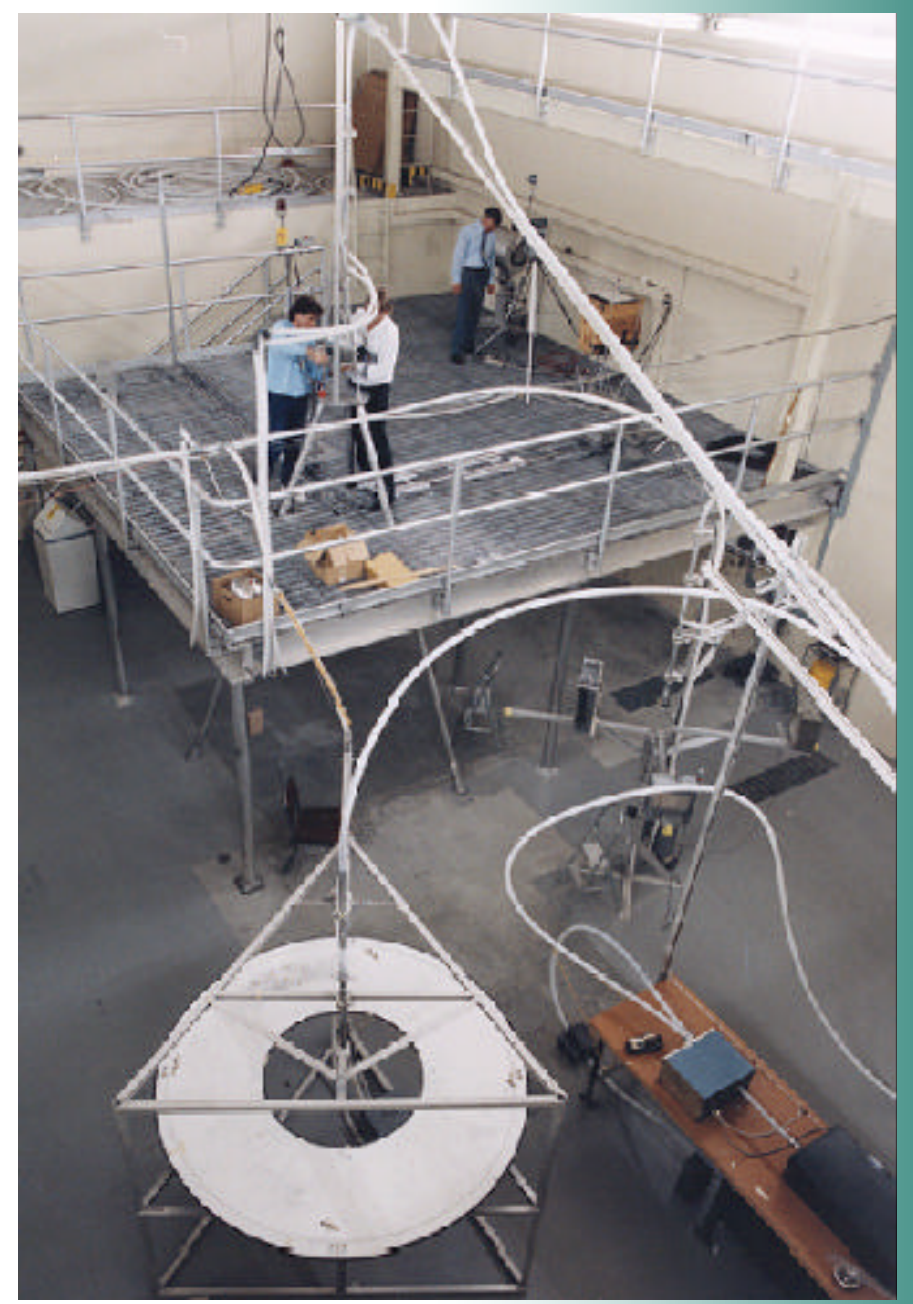

Figure 2.4. The Laboratory's Low-Scatter Room. This facility is suitable for neutron and photon irradiation of devices that may be sensitive to scattered radiation. The facility is equipped with two irradiation stations. The position shown at lower left is predominantly used for photon irradiations of personnel dosimeters using either ${ }^{137} \mathrm{Cs}$ or ${ }^{60} \mathrm{Co}$ sources. The position on the platform is located near the geometric center of the room and is used for neutron irradiations.

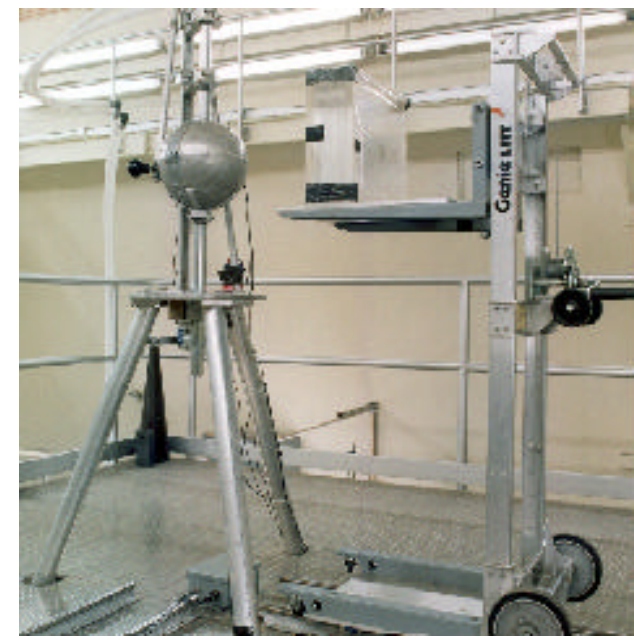

Figure 2.5. The Low-Scatter Room Tower Irradiation Position. This position allows for irradiation using photon or neutron sources. Neutron irradiations may be performed with either a bare source configuration or using a moderator assembly, such as the cadmiumcovered $\mathrm{D}_{2} \mathrm{O}$ sphere shown here. While most dosimeters are irradiated at a distance of $50 \mathrm{~cm}$ from the source, instrument calibrations are accomodated by a flexible positioning system, which has a range extending to about $3 \mathrm{~m}$. Based on room return evaluations, appropriate corrections are made to ensure that instrument calibrations are normalized to free-field conditions. 


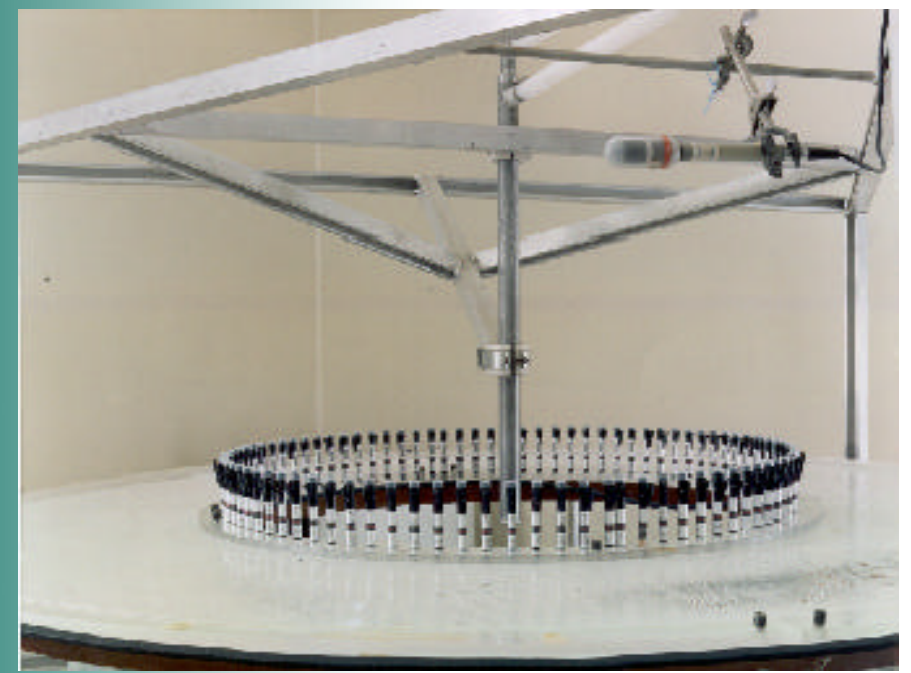

Figure 2.6. Floor-Level Station in the Low-Scatter Room. This station is used for photon irradiations. Dosimeters may be placed at distances from 50 to $100 \mathrm{~cm}$ from the source position. The supporting structure is composed of low atomic number materials and is rigid enough to prevent warping. With available positioning jigs, dosimeters may be placed at equal distances in circumference around the source position. An air-ionization chamber is available for irradiation quality control.
Additional sealed sources may be configured within the facility for special calibration or characterization needs. Current limitations on the facility mandate that sources generate no more than $100 \mathrm{mrem} / \mathrm{h}$ at a distance of $30 \mathrm{~cm}$. With this restriction, the sources currently used include ${ }^{137} \mathrm{Cs}$ (about $10 \mathrm{mCi}$ ), various beta sources (see Section 2.2.5) and an ${ }^{241} \mathrm{AmBe}$ (3 Ci) neutron source.

\subsubsection{Source Well Room}

Four calibration source wells are located in the calibration facility (see Figure 2.7). Each well is $0.3 \mathrm{~m} \mathrm{(1 \textrm {ft } )}$ in diameter by $10 \mathrm{~m}(33 \mathrm{ft})$ deep and contains a trolleymounted, double-encapsulated radionuclide source.

Table 2.1. Available Sources in 318 Building

\begin{tabular}{|c|c|c|c|}
\hline Source & Geometry & $\begin{array}{c}\text { Nominal } \\
\text { Rate/Range }^{(\mathbf{a})} \\
(\mathbf{R}[\mathrm{rem}] / \mathbf{h})\end{array}$ & $\begin{array}{c}\text { Primary Photon } \\
\text { Energy (MeV) }\end{array}$ \\
\hline \multirow{4}{*}{${ }^{60} \mathrm{Co}$} & Open $(4 \pi)$ & $0.6 / 2$ & \multirow{4}{*}{$1.17 / 1.33$} \\
\hline & Beam & $\begin{array}{c}2-750^{(\mathrm{b})} \\
26-8500^{(\mathrm{c})}\end{array}$ & \\
\hline & Beam & $\begin{array}{l}11.8-3700^{(\mathrm{b})} \\
135-42500^{(\mathrm{c})}\end{array}$ & \\
\hline & Open $(4 \pi)$ & $0-1.4 \mathrm{Mrad} / \mathrm{h}$ & \\
\hline \multirow{8}{*}{${ }^{137} \mathrm{Cs}$} & Well & $\begin{array}{c}10^{-4}-0.007^{(\mathrm{b})} \\
0.001-0.130^{(\mathrm{c})}\end{array}$ & \multirow{8}{*}{0.662} \\
\hline & Well & $0.025-2.700$ & \\
\hline & Well & $\begin{array}{c}0.004-1.3^{(\mathrm{b})} \\
0.065-22.0^{(\mathrm{c})}\end{array}$ & \\
\hline & Beam & $\begin{array}{c}.001-0.25^{(\mathrm{b})} \\
0.070-24.0^{(\mathrm{c})}\end{array}$ & \\
\hline & Open $(4 \pi)$ & $0.34 / 1.3$ & \\
\hline & Beam & $\begin{array}{c}0.008-2.5^{(\mathrm{b})} \\
0.7-240^{\text {(c) }}\end{array}$ & \\
\hline & Open $(4 \pi)$ & $1.8 / 6.8$ & \\
\hline & Beam & $2.3 / 21$ & \\
\hline${ }^{241} \mathrm{Am}$ & Open $(2 \pi)$ & 0.125 & 0.060 \\
\hline \multirow{2}{*}{$\begin{array}{c}{ }^{252} \mathrm{Cf} \\
\text { (bare) } \\
{ }^{252} \mathrm{Cf} \\
\text { (moderated) }\end{array}$} & Open $(4 \pi)$ & 2.6 to 0.071 & \multirow{4}{*}{ N/A } \\
\hline & Open $(4 \pi)$ & 0.617 to 0.0171 & \\
\hline $\begin{array}{l}{ }^{252} \mathrm{Cf} \\
\text { (bare) }\end{array}$ & Open $(4 \pi)$ & 0.0077 to 0.00021 & \\
\hline $\begin{array}{c}{ }^{252} \mathrm{Cf} \\
\text { (moderated) }\end{array}$ & Open $(4 \pi)$ & 0.0021 to 0.00006 & \\
\hline \multicolumn{4}{|c|}{$\begin{array}{l}\text { (a) Values separated by "”" indicate discrete calibration points. } \\
\text { Values separated by "." indicate inclusive range of calibrated rates. Rates current } \\
\text { as of mid-year } 1999 . \\
\text { (b) Attenuated }(\mathrm{Pb}) \\
\text { (c) Unattenuated }\end{array}$} \\
\hline
\end{tabular}




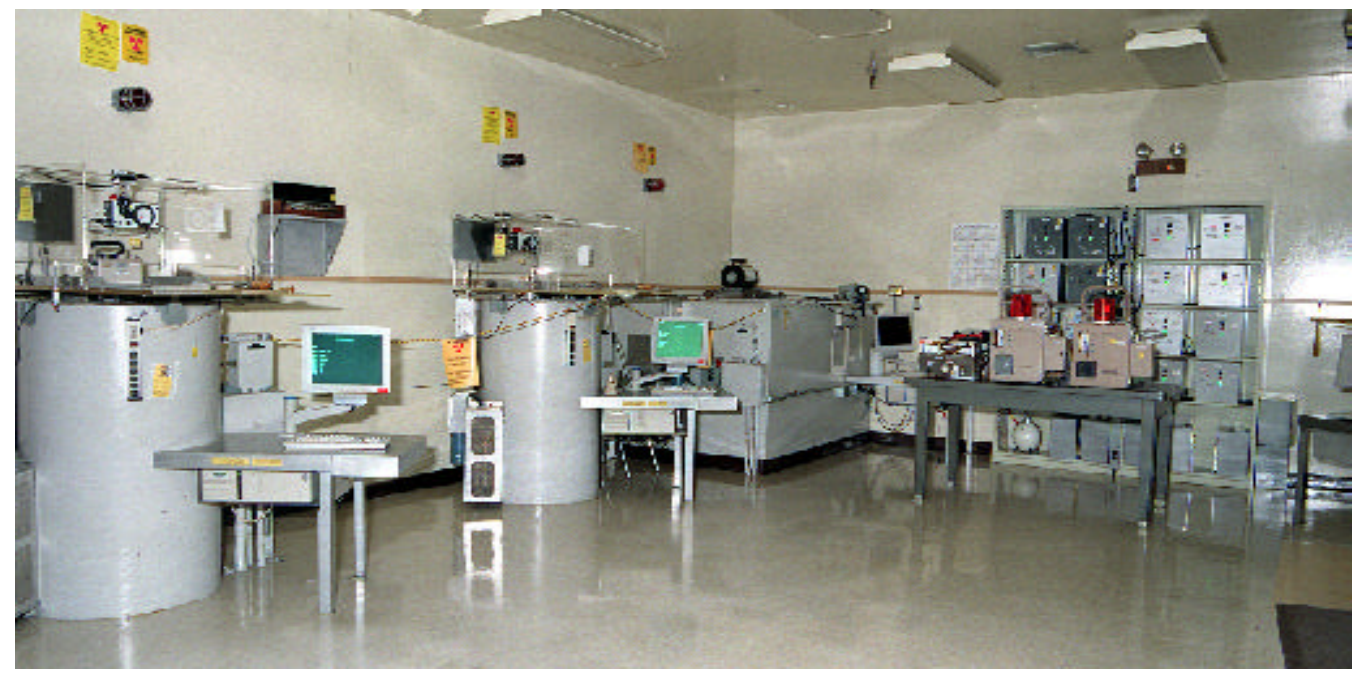

Figure 2.7. Well Room with Three ${ }^{137}$ Cs Wells (cylindrical shields; one not shown) and One ${ }^{252} \mathrm{Cf}$ Well (square block in back corner). The well room allows for rapid calibration of exposure rate instruments from about $0.1 \mathrm{mR} / \mathrm{h}$ to $17 \mathrm{R} / \mathrm{h}$.

Trolley movement is controlled by a dedicated personal computer programmed to position the source to provide the desired exposure or dose equivalent rate at the top of the well (see Figure 2.8). Source-todetector distances are automatically corrected to compensate for temperature, pressure, and source decay. Wells 1,2 and 4 contain $0.34 \mathrm{Ci}, 17.5 \mathrm{Ci}$, and $7 \mathrm{Ci}$ of ${ }^{137} \mathrm{Cs}$, respectively, and provide $662-\mathrm{keV}$ photon fields from less than $100 \mu \mathrm{r} / \mathrm{h}$ to approximately $17 \mathrm{R} / \mathrm{h}$. Well 3 contains $62 \mathrm{mCi}$ (as of 5/99) of ${ }^{252} \mathrm{Cf}$, which provides neutron dose equivalent rates from $1 \mathrm{mrem} / \mathrm{h}$ up to $750 \mathrm{mrem} / \mathrm{h}$ for select neutron monitors. This well is calibrated specifically for each type of detector used to enable the accurate reflection of free-field conditions. Currently, it is configured for NRC AN/PDR-7O "Snoopy"- and Eberline NRD-based detector reference to bare ${ }^{252} \mathrm{Cf}$. Together, the calibration wells make it possible to perform instrument calibrations and evaluations over a wide range of exposure rates with minimum radiation exposure to the operator.

\subsubsection{X-Ray Facilities and Capabilities}

The $\mathrm{x}$-ray laboratory consists of a shielded control panel (Figure 2.9) and a 4.7-m x 12.6- $\mathrm{m} \times 4.0-\mathrm{m}(15-\mathrm{ft} \times 41-\mathrm{ft} \times 13-\mathrm{ft})$ irradiation room. Two identical Philips Model-324 x-ray machines (Figure 2.10) are currently used to support PNNL instrument calibration/personnel dosimetry activities. One machine produces bremsstrahlung photon spectra (e.g., National Institute of Standards and Technology [NIST] and International Standards Organization [ISO] techniques), while the second is configured to facilitate production of $\mathrm{K}$-fluorescence technique (i.e., narrow) secondary photon spectra (e.g., F-Mo, F-W) within a shielded enclosure (Figure 2.11). Tables 2.2 through 2.4 provide complete lists of available techniques and their characteristics. Both x-ray-generating systems use laser-alignment systems to aid in device (instrument/dosimeter) positioning.

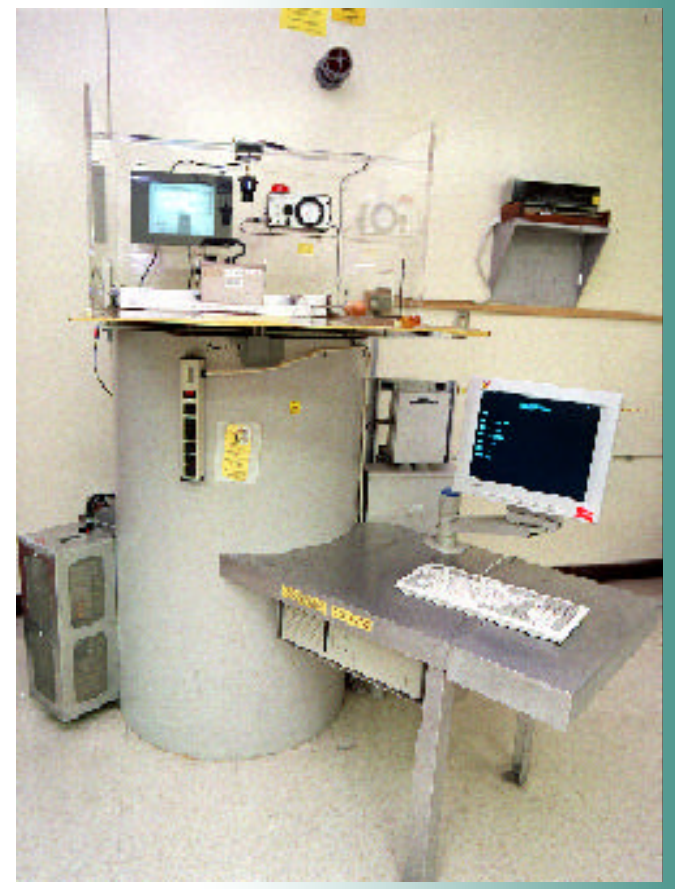

Figure 2.8. Well 1 in the 318 Building Well Room. This photo shows the camera and flat panel display (above well, back left) for monitoring instrument response during irradiations; the weather station (mounted on wall to the right of the well) for compensating for pressure and temperature changes; and the computer station for controlling source position within the well. 


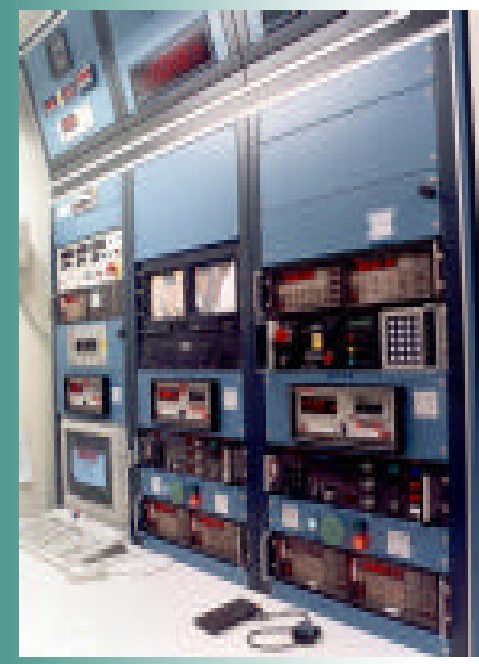

Figure 2.9. Control Panel. A single technican can operate and monitor three separate irradiation/calibration devices simultaneously from this panel (i.e., the Shepherd irradiator or Pantak $x$-ray machine, one of the two Philips $x$-ray machines, and the ${ }^{241} \mathrm{Am}$ irradiator).

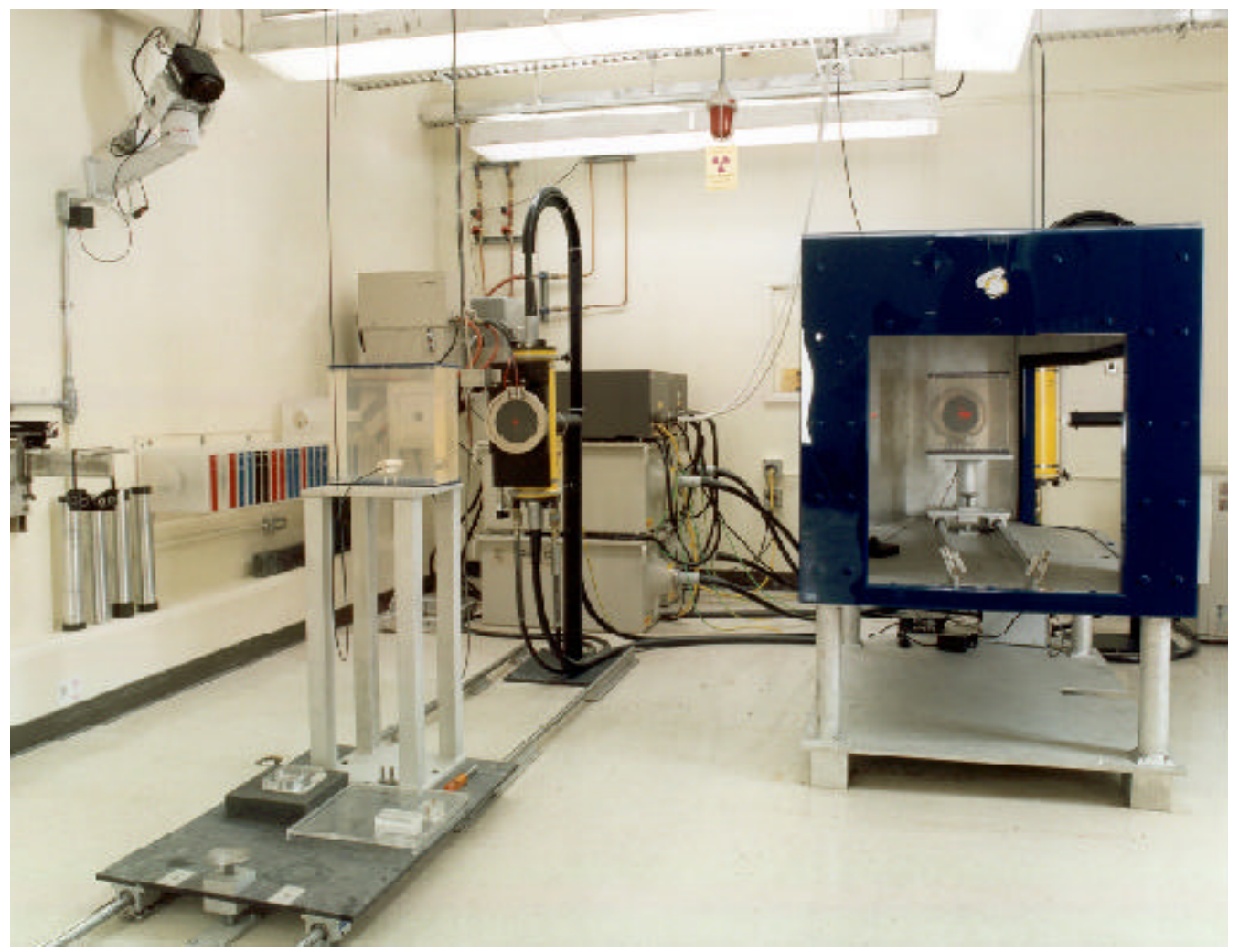

Figure 2.10. Two Philips Model 324 X-Ray Units. Both are available for performing various dosimeter irradiations and instrument reponse evaluations. The unit on the left is configured to produce most NIST and several ISO techniques. The unit on the right is used for generating ISO/K-fluorescence techniques, which are useful for specific photon energy response evaluations from energies as low as $8.6 \mathrm{keV}$ to $59.3 \mathrm{keV}$.

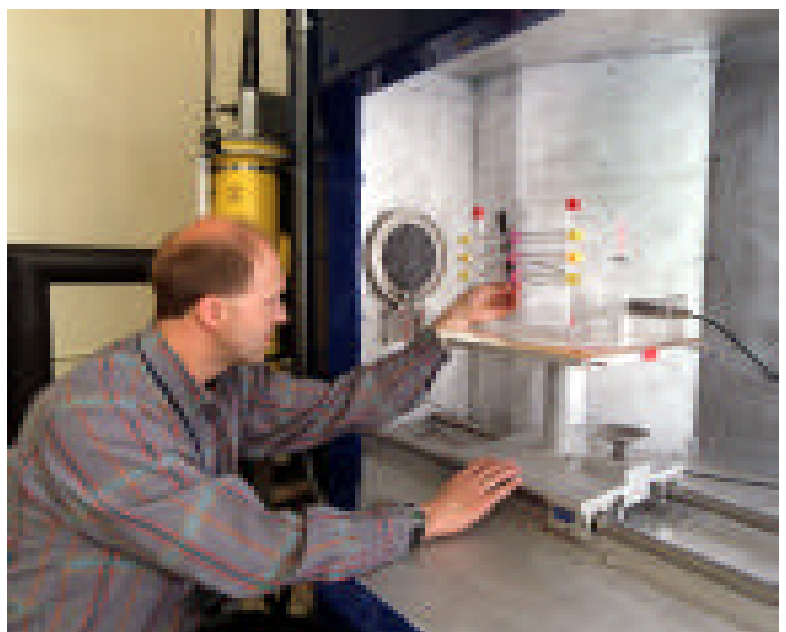

Figure 2.11. Philips Model 324 X-Ray Machine. $K$-fluorescence beams are extracted at a $90^{\circ}$ angle from the incident $x$-ray beam direction. A special shielded enclosure is used by PNNL to maintain "clean" spectra.
Traceability of calibrations to the NIST is maintained through intercomparison standards. An ongoing measurement quality assurance interaction (proficiency testing) with NIST further strengthens the NIST/PNNL link.

The PNNL $\mathrm{x}$-ray facilities offer quality-controlled irradiation application for both photon detector response characterization and personnel dosimetry systems following current DOE, ISO, and ANSI standards. 
Table 2.2. Available NIST-Specified Bremsstrahlung X-Ray Reference Fields (2000 Data)

\begin{tabular}{|c|c|c|c|c|c|c|c|}
\hline \multirow{2}{*}{ Technique } & Energy (keV)(a) & \multicolumn{2}{|c|}{$\begin{array}{c}\text { Half-Value Layer } \\
\text { (mm Al) }\end{array}$} & \multicolumn{2}{c|}{$\begin{array}{c}\text { Homogeneity } \\
\text { Coefficient (Al) }\end{array}$} & \multicolumn{2}{c|}{ Exposure Rate (R/h) } \\
\cline { 2 - 8 } & $\begin{array}{c}\text { Average or } \\
\text { (Effective) }\end{array}$ & Philips & Pantak & Philips & Pantak & Minimum & Maximum \\
\hline M20 & 14 & 0.150 & 0.149 & 0.79 & 0.76 & 2.9 & 290 \\
\hline M30 & 20 & 0.352 & 0.368 & 0.63 & 0.68 & 3.2 & 330 \\
\hline M50 & 29 & 1.005 & 1.016 & 0.64 & 0.64 & 3.4 & 350 \\
\hline M60 & 35 & 1.640 & 1.738 & 0.72 & 0.70 & 3.2 & 310 \\
\hline M100 & 53 & 4.880 & 5.089 & 0.71 & 0.72 & 1.5 & 300 \\
\hline M150 & 73 & 9.870 & 10.30 & 0.85 & 0.86 & 3.8 & 390 \\
\hline M200 & 100 & 14.62 & 15.10 & 0.94 & 0.93 & 4.3 & 430 \\
\hline S60 & 38 & 2.650 & 2.850 & 0.71 & 0.77 & 0.6 & 120 \\
\hline S75 & 40 & 1.817 & 1.928 & 0.61 & 0.62 & 4.6 & 470 \\
\hline H40 & 33 & 2.976 & 3.003 & 0.92 & 0.90 & 0.02 & 4.2 \\
\hline H50 & $(38)$ & 4.070 & 4.398 & 0.90 & 0.91 & 0.05 & 9.4 \\
\hline H100 & $(80)$ & 13.49 & 13.98 & 1.01 & 0.98 & 0.02 & 3.1 \\
\hline H150 & $(120)$ & 17.19 & 17.49 & 1.01 & 0.97 & 0.12 & 16 \\
\hline H200 & $(166)$ & 19.46 & 20.31 & 0.98 & 0.98 & 0.09 & 9.2 \\
\hline H250 & $(211)$ & 21.67 & 22.46 & 0.99 & 0.96 & 0.09 & 8.5 \\
\hline H300 & $(251)$ & 23.31 & 23.41 & 0.97 & 1.00 & 0.09 & 9.4 \\
\hline (a) Nominal & & & & & & \\
\hline
\end{tabular}

Table 2.3. Available ISO-Specified Bremsstrahlung X-Ray Reference Fields - Philips System

\begin{tabular}{|c|c|c|c|c|c|c|}
\hline \multirow[b]{2}{*}{ Technique } & \multicolumn{2}{|c|}{ Energy $(\mathrm{keV})^{(\mathrm{a})}$} & \multirow{2}{*}{$\begin{array}{l}\text { Half-Value Layer } \\
\quad(\mathrm{mm}) \\
\mathrm{Al}\end{array}$} & \multirow{2}{*}{$\begin{array}{c}\text { Homogeneity } \\
\text { Coefficient } \\
\text { Al }\end{array}$} & \multicolumn{2}{|c|}{ Exposure Rate (R/h) } \\
\hline & Average & Resolution(b) & & & Minimum & Maximum \\
\hline \multicolumn{7}{|c|}{ Narrow Series } \\
\hline NS 150 & 118 & 37 & 16.97 & 1.00 & 0.14 & 21.0 \\
\hline NS 250 & 208 & 28 & 21.68 & 0.98 & 0.06 & 6.0 \\
\hline \multicolumn{7}{|c|}{ High Air Kerma Rate Series } \\
\hline HK 60 & 37.3 & \multirow{3}{*}{ (c) } & 2.30 & 0.73 & 1.5 & 300 \\
\hline HK 100 & 57.4 & & 6.26 & 0.81 & 2 & 390 \\
\hline HK 250 & 122 & & 16.74 & 0.96 & 6.5 & 650 \\
\hline \multicolumn{7}{|c|}{$\begin{array}{l}\text { (a) Nominal (per ISO } 4037-1[1996]) \\
\text { (b) Full width, half maximum }(\mathrm{FWHM})(\Delta \mathrm{E} / \mathrm{E} * 100 \text {, where } \Delta \mathrm{E} \text { represents the spectrum width corresponding to half the maximum } \\
\text { ordinate of the spectrum) } \\
\text { (c) Not specified }\end{array}$} \\
\hline
\end{tabular}


Table 2.4. Available K-Fluorescence Reference X-Ray Fields

\begin{tabular}{|c|c|c|c|c|c|}
\hline \multirow[b]{2}{*}{ Technique $^{(\mathbf{a})}$} & \multirow{2}{*}{$\begin{array}{c}\text { Theoretical } \\
\text { Peak Energy } \\
(\mathrm{keV})^{(\mathbf{b})}\end{array}$} & \multicolumn{3}{|c|}{ Production Method } & \multirow[b]{2}{*}{$\begin{array}{l}\text { Exposure Rate } \\
\qquad(\mathbf{R} / \mathbf{h})^{(\mathbf{b}, \mathbf{c})}\end{array}$} \\
\hline & & $\begin{array}{c}\text { Radiator/ } \\
\text { Attenuator }\end{array}$ & Filter & $\mathbf{k V p}$ & \\
\hline F-Zn & 8.6 & Zinc & None & 50 & $0.13-19.8$ \\
\hline $\mathrm{F}-\mathrm{Zr}$ & 15.8 & Zirconium & $\mathrm{SrCO}_{3}$ & 80 & $0.02-3.2$ \\
\hline F-Mo & 17.5 & Molybdenum & $\mathrm{Zr}$ & 80 & $0.02-3.4$ \\
\hline F-Sn & 25.3 & Tin & $\mathrm{Ag}$ & 100 & $0.02-3.5$ \\
\hline F-Cs & 31.0 & Cesium & $\mathrm{TeO}_{2}$ & 100 & $0.02-3.2$ \\
\hline $\mathrm{F}-\mathrm{Nd}$ & 37.4 & Neodymium & $\mathrm{Ce}$ & 110 & $0.009-1.4$ \\
\hline F-Sm & 40.1 & Samarium & $\mathrm{CeO}_{2}$ & 120 & $0.01-1.4$ \\
\hline F-Er & 49.1 & Erbium & $\mathrm{Gd}_{2} \mathrm{O}_{3}$ & 120 & $0.005-0.8$ \\
\hline $\mathrm{F}-\mathrm{W}_{\mathrm{e}}$ & 59.3 & Tungsten & $\mathrm{Yb}_{2} \mathrm{O}_{3}$ & 170 & $0.005-0.8$ \\
\hline $\bar{F}-\mathrm{W}_{\mathrm{m}}$ & 59.3 & Tungsten & $\mathrm{Yb}$ & 170 & $0.006-0.9$ \\
\hline
\end{tabular}

(a) As identified by ISO 4037-3 (1996). Subscripts on F-W techniques differentiate between filters made of chemical compound (c) and pure metal (m). All techniques use a 1.0-mm aluminum prefilter with the exception of the F-Zn technique, which uses a 5-mm pre-filter.

(b) Nominal

(c) Minimum/maximum estimated at $0.1 / 15.0 \mathrm{~mA}$

(d) Demonstrated traceability is established through measurement intercomparison with the United Kingdom's National Radiation Protection Board (NRPB).

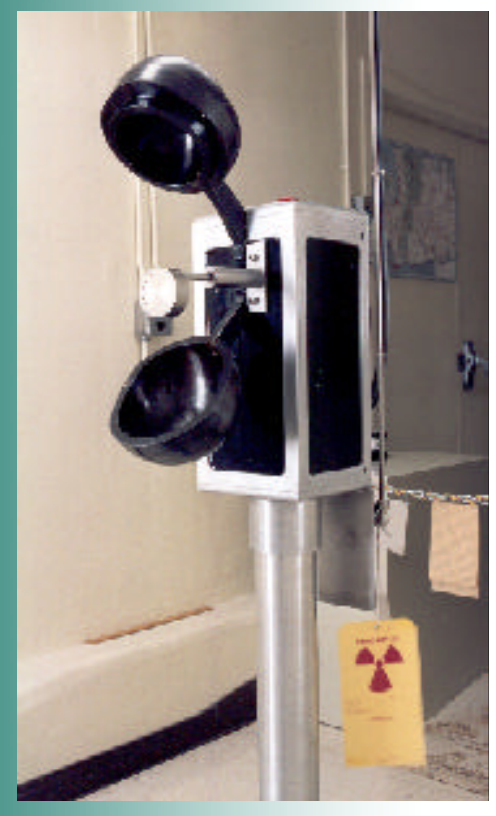

Figure 2.12. $A n^{241} \mathrm{Am}$ Source. This source provides a $60-\mathrm{keV}$ photon calibration field.

\section{${ }^{241}$ Am Exposure Laboratory}

A modified Atlan-Tech irradiator (see Figure 2.12) is used to irradiate dosimeters and calibrate instruments to low-energy $(60-\mathrm{keV})$ gamma radiation. This irradiator is equipped with an Amersham Model AMC50, $185 \mathrm{GBq}(5 \mathrm{Ci}),{ }^{241} \mathrm{Am}$ source. The active area of the source is $40 \mathrm{~mm}$ in diameter and is encapsulated on the front side by 0.25 - to $0.30-\mathrm{mm}$ of stainless steel. The $2 \pi$ reference field is calibrated at a distance of $50 \mathrm{~cm}$, providing an air kerma rate of approximately $1 \mathrm{mGy} / \mathrm{h}(0.12 \mathrm{R} / \mathrm{h})$.

\section{Shepherd Irradiator}

A J.L. Shepherd, Model 81 Irradiator (see Figure 2.13) is used to perform dosimetry irradiations and calibrations of reference/transfer standard instrumentation for gamma radiation. This irradiator employs a $3.7-\mathrm{TBq}(100-\mathrm{Ci}){ }^{137} \mathrm{Cs}$ source and emits a $30^{\circ}$ collimated photon beam. The reference field is calibrated at two distances on the beam axis, 1 and $3 \mathrm{~m}$, which provides air kerma rates of approximately $176 \mathrm{mGy} / \mathrm{h}(20 \mathrm{R} / \mathrm{h})$ and $19 \mathrm{mGy} / \mathrm{h}(2.2 \mathrm{R} / \mathrm{h})$, respectively.

\subsubsection{High-Exposure Facility}

The high-exposure facility (see Figure 2.14) is capable of delivering a uniform gamma radiation field of $0.08 \mathrm{R} / \mathrm{h}$ to $>5 \times 10^{4} \mathrm{R} / \mathrm{h}$ for standard calibration of testing or radiation measuring instruments. Table 2.1 includes the current radiation sources and exposure capabilities of the facility.

The high-exposure facility has two ${ }^{137} \mathrm{Cs}$ and two ${ }^{60} \mathrm{Co}$ encapsulated sources that are pneumatically raised into exposure position from a shielded storage location. 


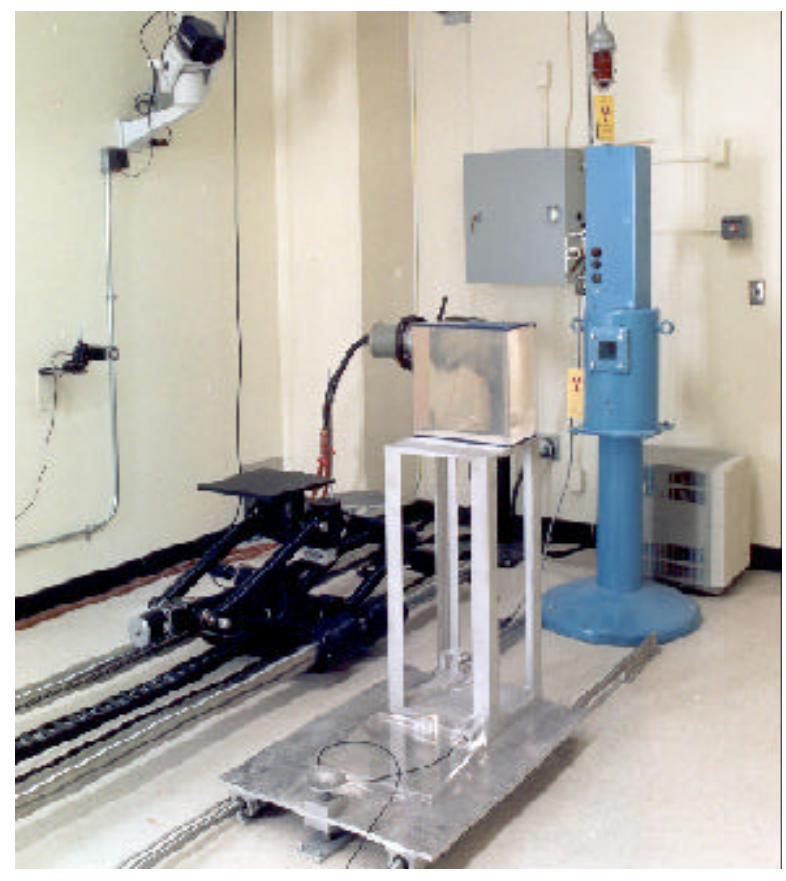

Figure 2.13. The J.L. Shepherd Model 81, 100-Ci

${ }^{137} \mathrm{Cs}$ Irradiator (right). This equipment is available for performing dosimeter irradiations or instrument calibrations from up to a distance of $4 \mathrm{~m}$. A Pantak Model HF320C x-ray machine (left and behind the phantom) is available for generating NIST and ISO beam techniques. The associated $x$-ray irradiation platform is capable of rotating and can be used to perform static and dynamic angular response studies.
In the exposure position, the source capsule is shielded by a 21/2-ton lead-shielded exposure column that establishes the exposure (beam) geometry. A $30^{\circ}$-conical opening $\left(15^{\circ}-\right.$ cone angle) presents a horizontal radiation field for instrument exposure about $1.5 \mathrm{~m}(5 \mathrm{ft})$ above the floor. Instrument detectors are placed on a lightweight aluminum trolley cart on rails in front of the cone opening. A motor moves the trolley cart along the rail system. The precise location is transmitted from an optical position transducer to the remote console. The 6-m- (19-ft-) long rails provide a 140: 1 ratio in available exposure rates for each source.

Once the detector has been positioned on the trolley cart and connected to a remote readout, all operations may be conducted at the remote operating console located outside the concrete-shielded exposure room. Cabling runs from the trolley cart to the remote console for most radiation instruments. For instruments that cannot be operated remotely, a closed-circuit TV camera is used to monitor instrument responses from the operator console (Figure 2.15). From the remote control console, the sources can be rotated into alignment with the exposure column and raised to exposure position. The trolley cart can also be positioned and repositioned to any location along the length of the track. The combination of long trolley track and the variety of sources allows a wide range of exposure rates to be generated within the facility (from $80 \mathrm{mR} / \mathrm{h}$ to over $50,000 \mathrm{R} / \mathrm{h}$ ).

The exposure room measures $15.2 \mathrm{~m}$ x $3.7 \mathrm{~m} \times 3.7 \mathrm{~m}(50 \mathrm{ft} \times 12 \mathrm{ft}$ $\mathrm{x} 12 \mathrm{ft}$ ) in size. The beam is centered between the side walls and is

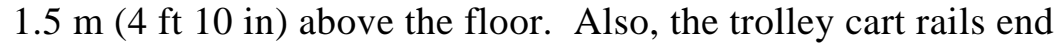
$1.8 \mathrm{~m}$ ( $6 \mathrm{ft})$ away from the back wall. In this way, the solid surfaces are far enough away that any reflected radiation is insignificant compared to the incident beam.

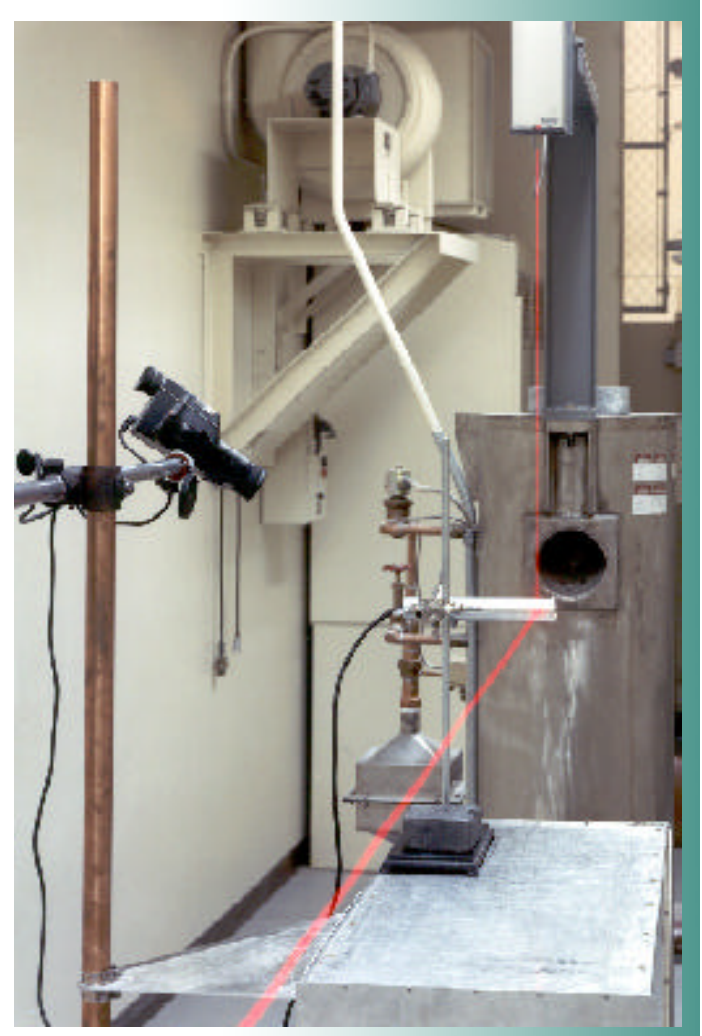

Figure 2.14. The High-Exposure Facility. This facility is used for high-level ${ }^{137} \mathrm{Cs}$ and ${ }^{60}$ Co photon irradiations and calibrations. The irradiation unit pneumatically lifts the source into the irradiation position. This facility is equipped with positioning lasers that aid initial setup of dosimeters or instruments within the central beam axis at a distance of $1 \mathrm{~m}$. Cameras are positioned to remotely monitor instrument readings during irradiation. 


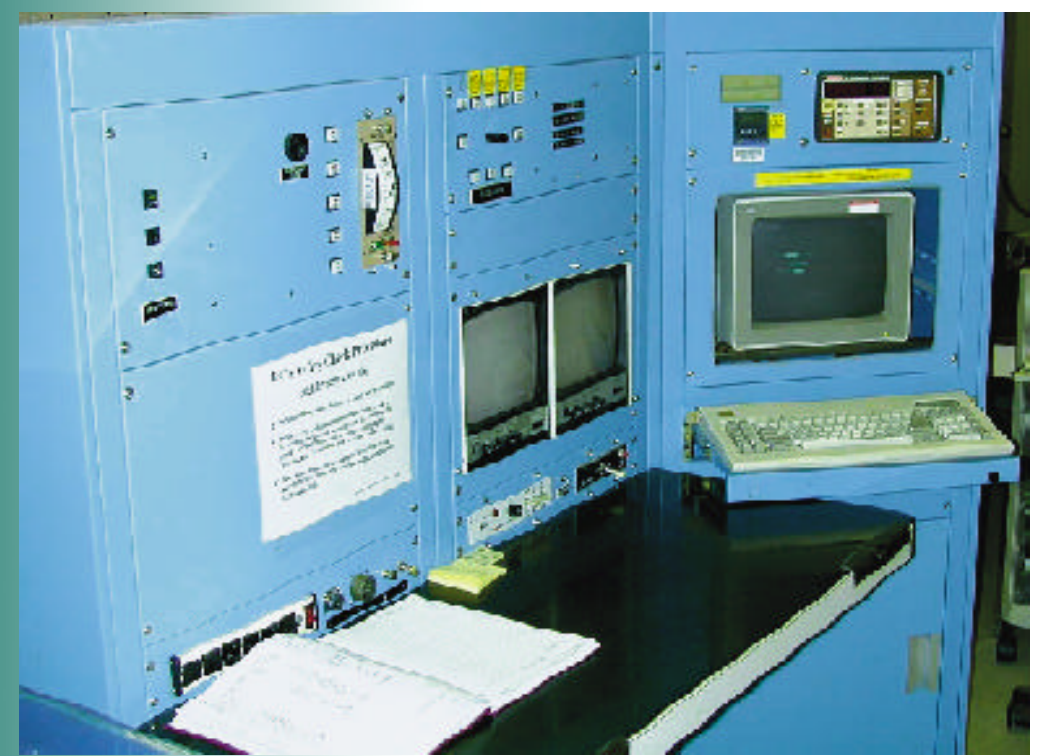

Figure 2.15. The High-Exposure Facility Control Room. The facility remotely controlled from the panel shown above, which also houses the monitors for remote cameras within the radiation area and allows for remote positioning of instruments, once the 1-m offset is established using the positioning lasers.

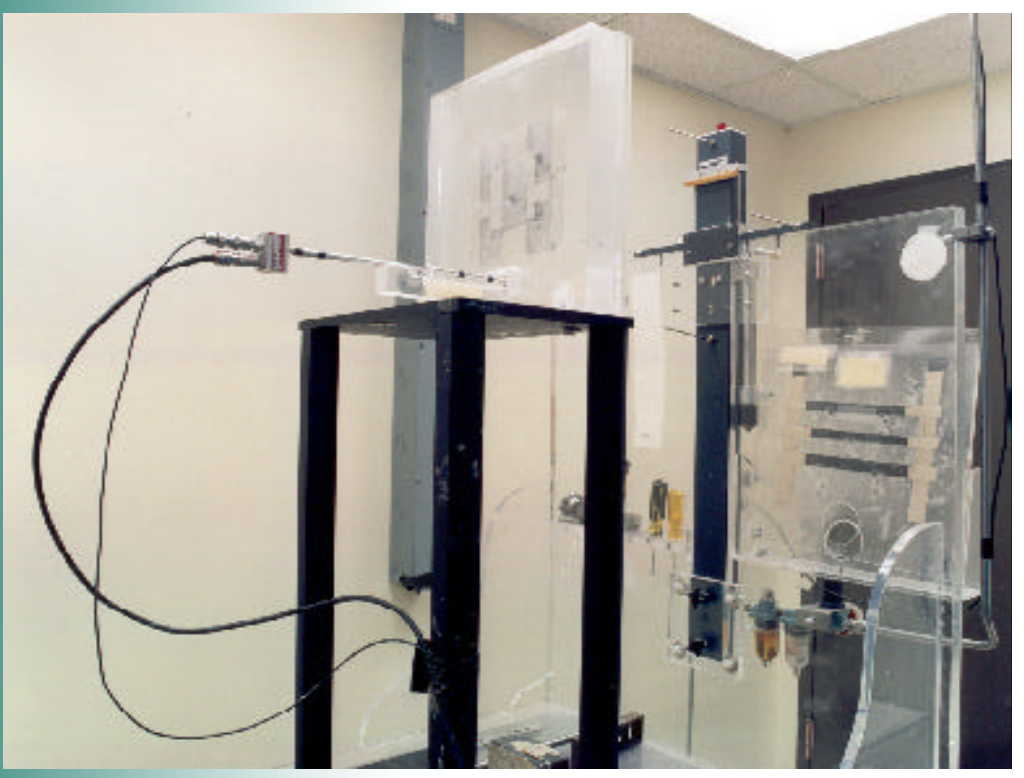

Figure 2.16. A Buchler-Amersham Irradiation Jig and Point Source Inventory are the Basis for PNNL's Beta Irradiations. The original apparatus has been modified by replacing the pivot shutter with a pneumatic guillotine shutter. The system has been configured to be computer controlled for automated exposures and to monitor critical quality control information such as temperature, pressure, humidity, and the signal from an ionization chamber mounted in the phantom used for dosimeter irradiations (shown here).
The four sources are in a five-position, shielded carousel located below the floor level. From this carousel, the capsules are raised to exposure position like a rotameter float by the aircirculation pump that blows air up from under the carousel.

\subsubsection{Beta Standards Laboratory}

The 318 Building contains a beta calibration apparatus (manufactured by Amersham Buchler). The apparatus (shown in Figure 2.16) consists of a source jig, an operator console, and various beta sources. Dosimeters mounted on phantoms and instruments are irradiated within the beam; beam uniformity is enhanced by beam-flattening filters.

Four sources are included with the original Physikalisch-Techische Bundesanstalt (PTB) secondary standard source set, including: 1) a 50 - $\mathrm{mCi}(1,850-\mathrm{MBq}){ }^{90} \mathrm{Sr} /{ }^{90} \mathrm{Y}$ source, 2) a 2 $\mathrm{mCi}(74-\mathrm{MBq}){ }^{90} \mathrm{Sr} /{ }^{90} \mathrm{Y}$ source, 3) a $0.5-\mathrm{mCi}$ $(18.5-\mathrm{MBq})^{204} \mathrm{Tl}$ source, and 4) a $14-\mathrm{mCi}$ $(518-\mathrm{MBq}){ }^{147} \mathrm{Pm}$ source. The latter two sources have nearly decayed beyond practical use for most applications.

Amersham and Isotope Products Laboratory, in accordance with the ISO 6980 (1984), have constructed additional sources. A complete list of available sources is provided in Table 2.5

\subsubsection{Radiological Calibration Laboratories}

The calibration facility has several multipurpose laboratories designed to provide the flexibility required to calibrate a wide range of portable and semiportable radiological instrumentation and radioactive sources. The laboratories are fully equipped with a variety of electronic gear, including nuclear pulse generators, digital voltmeters, multichannel analyzers, highvoltage power supplies, amplifiers oscilloscopes, and scalers. A variety of small alpha-, beta- and gamma-emitting radionuclide sources are also available. The types of instruments 
Table 2.5. Available Beta Reference Fields

\begin{tabular}{|c|c|c|c|c|c|}
\hline Geometry & Isotope & $\begin{array}{l}\text { Window } \\
\text { Material and } \\
\text { Areal Density } \\
\left(\mathrm{mg} / \mathrm{cm}^{2}\right)\end{array}$ & $\begin{array}{l}\text { Protective Coating } \\
\text { Material and } \\
\text { Areal Density } \\
\left(\mathrm{mg} / \mathrm{cm}^{2}\right)\end{array}$ & $\begin{array}{l}\text { Residual Maximum } \\
\text { Energy }-E_{\text {res }}(\mathrm{MeV}) \\
\text { (M-Measured, } \\
\text { T-Theoretical) } \\
\end{array}$ & $\begin{array}{l}\text { Absorbed Dose } \\
\text { Rate(a) (rad/h) } \\
\text { (Calibration } \\
\text { Distance }[\mathrm{cm}])\end{array}$ \\
\hline \multirow{7}{*}{ Point } & ${ }^{147} \mathrm{Pm}$ & Not available & Titanium (2.3) & $0.1504(\mathrm{M})$ & $0.06(20)$ \\
\hline & $\begin{array}{l}{ }^{204} \mathrm{Tl} \\
{ }^{204} \mathrm{Tl}\end{array}$ & $\begin{array}{l}\text { Silver (20) } \\
\text { Glass (6.6) }\end{array}$ & $\begin{array}{c}\text { Gold (5) } \\
\text { Kapton }(\sim 0.8)\end{array}$ & $\begin{array}{c}0.53 \leq \mathrm{E}_{\text {res }} \leq 0.76(\mathrm{~T}) \\
0.608(\mathrm{M})\end{array}$ & $\begin{array}{c}0.006(30) \\
0.8(35)\end{array}$ \\
\hline & ${ }^{85} \mathrm{Kr}$ & Not available & Not available & Not available & $2.9(50)$ \\
\hline & $90 \mathrm{Sr} / 90 \mathrm{Y}$ & Silver (50) & Stainless steel $(\sim 75)$ & $1.80 \leq \mathrm{E}_{\text {res }} \leq 2.274(\mathrm{~T})$ & $0.48(30)$ \\
\hline & ${ }^{90 \mathrm{Sr} / 90 \mathrm{Y}}$ & Titanium (100) & Aluminum (20) & Not available & $0.44(35)$ \\
\hline & ${ }^{90} \mathrm{Sr} /{ }^{90} \mathrm{Y}$ & Silver (50) & Stainless steel $(\sim 75)$ & $2.046(\mathrm{M})$ & $19(30)$ \\
\hline & $\begin{array}{c}90 \mathrm{Sr} / 90 \mathrm{Y} \\
14 \mathrm{C}\end{array}$ & $\begin{array}{l}\text { Titanium }(100) \\
\text { Not available }\end{array}$ & $\begin{array}{l}\text { Not available } \\
\text { PMMA(b) }\end{array}$ & \multirow{6}{*}{$\begin{array}{l}\text { Has not been } \\
\text { measured for these } \\
\text { sources. }\end{array}$} & $\begin{array}{l}13(35) \\
2.2(0.2)\end{array}$ \\
\hline \multirow{5}{*}{ Distributed } & ${ }^{147} \mathrm{Pm}$ & Not available & Kapton (1.5) & & $0.37-0.006(0.2-15)$ \\
\hline & $204 \mathrm{Tl}$ & Not available & Kapton (9.5) & & $0.70-0.03(0.2-30)$ \\
\hline & ${ }^{90} \mathrm{Sr} / 90 \mathrm{Y}$ & Not available & Kapton (23.5) & & $4.09-0.16(0.2-30)$ \\
\hline & ${ }^{106} \mathrm{Ru} /{ }^{106} \mathrm{Rh}$ & Not available & Kapton (30.7) & & $<0.01(0.2)$ \\
\hline & $\begin{array}{c}\text { Depleted } \\
\text { uranium } \\
\end{array}$ & Not available & Aluminized mylar (7) & & $0.204(0.15)$ \\
\hline \multicolumn{6}{|c|}{$\begin{array}{l}\text { (a) Nominal at } 7 \mathrm{mg} / \mathrm{cm}^{2} \text { as of mid-year (1999) } \\
\text { (b) The source is polymerized with the Polymethylemethacrylate. Sheet thickness is approximately } 1 \mathrm{~mm} \text { with } \\
\text { activity uniformly distributed throughout. }\end{array}$} \\
\hline
\end{tabular}

calibrated in the laboratories include portable instruments as well as area radiation monitors, air monitors, personnel contamination monitors, and hand and shoe counters. Alpha, beta, and gamma instrument response check sources are also calibrated in these laboratories using standards that are explicitly traceable to NIST.

\subsubsection{Measuring and Test Equipment Calibration Laboratory}

The M\&TE Calibration Laboratory provides the flexibility to calibrate a wide range of physical and electrical instruments. These rooms are fully equipped with a variety of NIST-traceable physical and electrical standards that allow for calibration of instruments that measure voltage, current, resistance, capacitance, frequency, temperature, humidity, dew point, pressure, vacuum, gas flow, $\mathrm{pH}$, conductivity, time, rotational speed, and wind speed. Calibrations are performed in accordance with ANSI/NCSL Z540-1 (1994).

\subsubsection{Environmental Effects Laboratory}

In addition to routine calibration and evaluation capabilities, the Radiological Standards and Calibration Laboratory also possesses specialized testing capabilities that allow for controlled, operational evaluations of health physics instrumentation to be performed against ANSI performance standards (e.g., ANSI N42.17A and ANSI N42.17C [ANSI 1989a; 1989b]). This fully operational laboratory is designed to characterize the effects of temperature, pressure, humidity, vibration, 
acceleration, ac power, and microwave/radiofrequency $[\mathrm{RF}] /$ electromagnetic (EM) fields on operational instrumental responses. These capabilities are routinely used to type test new instruments. New instruments are type tested using environmental chambers, mechnical vibration and shock testing equipment, non-ionizing radiation environments, and for $\mathrm{AC}$ power and line noise susceptibility as follows:

\section{Environmental Chambers.}

Environmental chambers are available with temperature and relative humidity $(\mathrm{RH})$ ranges of $-70^{\circ} \mathrm{C}$ to $170^{\circ} \mathrm{C}$ and $5 \%$ to 95\% RH (see Figure 2.17). Condensing environments can be created in the chambers. Fine mists, rain, and corrosive environments are generated in a salt/fog chamber. A pressure/vacuum chamber simulates atmospheric pressure from $26 \mathrm{kPa}$ to $370 \mathrm{kPa}$ (see Figure 2.18).

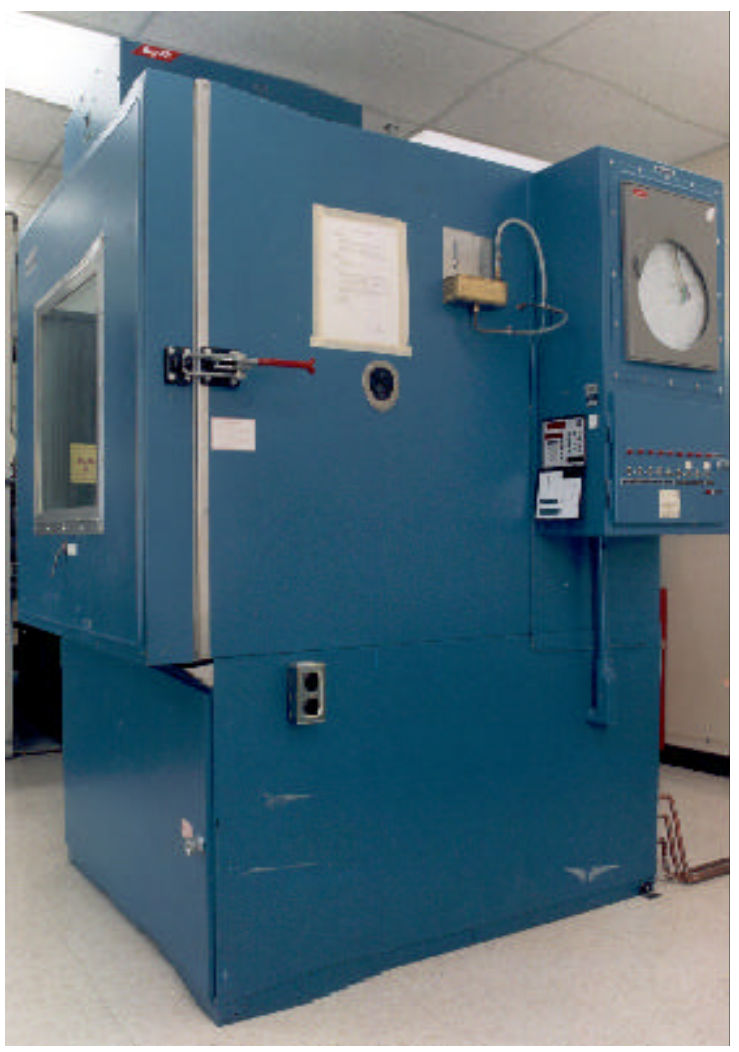

Figure 2.17. Environmental Chamber. This is one of two environmental chambers used by PNNL to evaluate instrument response to extreme temperatures and humidities. The range of the Russells chamber (shown) is $-68^{\circ} \mathrm{C}$ to $177^{\circ} \mathrm{C} ; 5 \%$ to $95 \%$ RH. The Tenney Chamber (not shown) has a range of $-20^{\circ} \mathrm{C}$ to $60^{\circ} \mathrm{C} ; 5 \%$ to $95 \% \mathrm{RH}$.

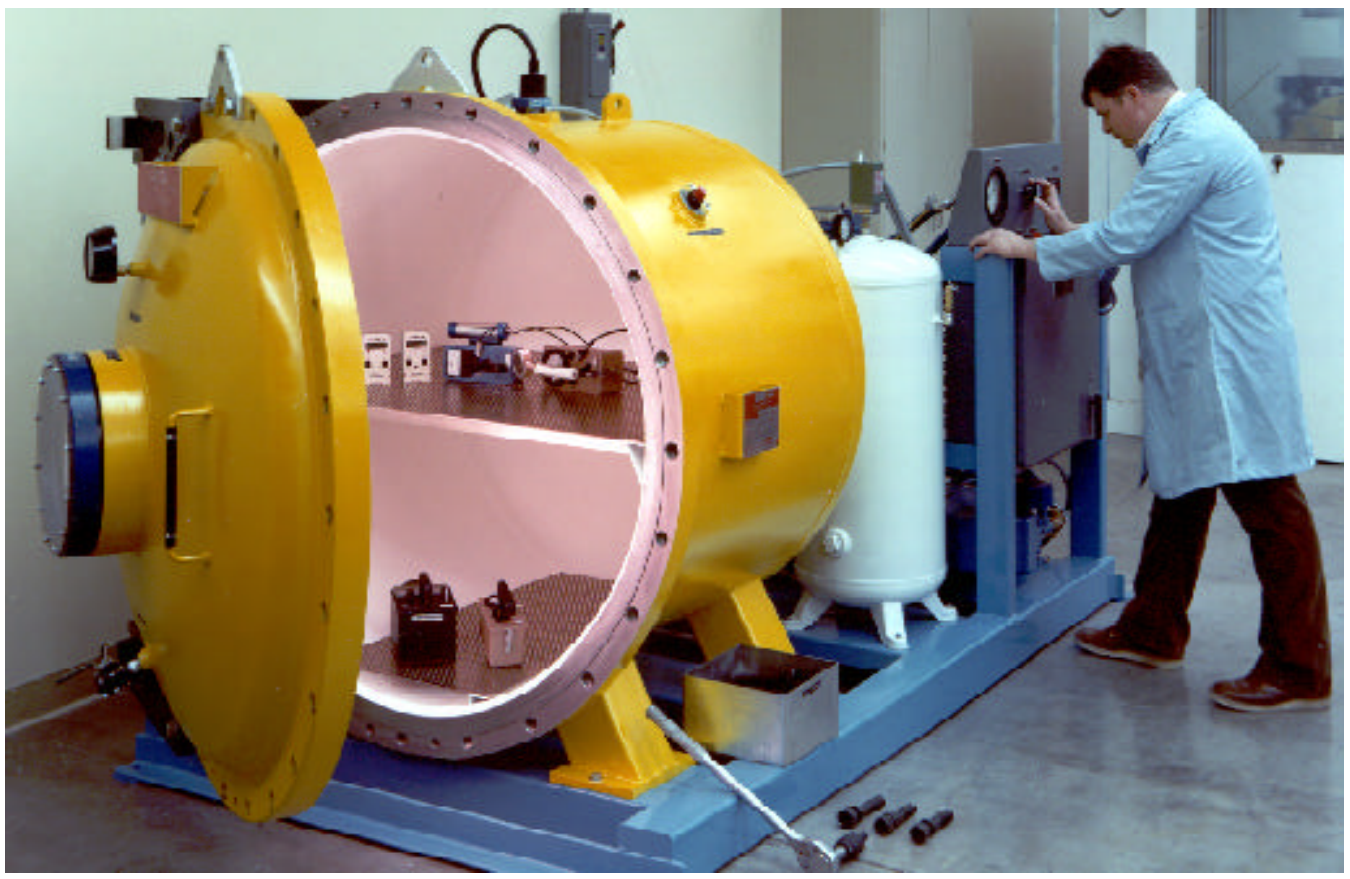

Figure 2.18. Pressure/Vacuum Chamber for Simulating Variations in Ambient Pressure Levels (volume: $1.4 \mathrm{~m}^{3}$; range: $26 \mathrm{kPa}$ to $370 \mathrm{kPa}$ ) 
- Mechanical. Instrument performance after and during mechanical vibrations and shocks is determined using a variety of test equipment, including two vibration tables and a mechanical shock generator.

Small payloads (up to $45 \mathrm{~kg}$ [100 lb]) are tested on a table with a maximum acceleration of $10 \mathrm{G}$, over the frequency range of 10 to $60 \mathrm{~Hz}$ (Figure 2.19). A computer controller can be used for high-range, random, and fine vibrations with the smaller table. Up to $680 \mathrm{~kg}(1500 \mathrm{lb})$ are tested on a vibration table with a maximum acceleration of $3.2 \mathrm{G}$ over the frequency range of 8 to $60 \mathrm{~Hz}$ (Figure 2.20). A maximum acceleration of $63 \mathrm{G}$ over the frequency range of 5 $\mathrm{Hz}$ to $10 \mathrm{kHz}$ is available with smaller test loads.

A mechanical shock generator produces mechanical shocks up to $100 \mathrm{G}$ (Figure 2.21).

Non-Ionizing Radiation Environments. Response to interfering non-ionizing radiations is determined using a variety of field-generating equipment. A parallel-plate antenna generates RF fields with a frequency range of $0.3 \mathrm{MHz}$ to $35 \mathrm{MHz}$ and field strength of $100 \mathrm{~V} / \mathrm{m}$ (upper piece of equipment in Figure 2.22. A transverse EM cell produces DC to $350-\mathrm{MHz}$ fields with a maximum field strength of $100 \mathrm{~V} / \mathrm{m}$. (beneath the parallel-plate antenna in Figure 2.22). A microwave exposure chamber generates fields at $2450 \mathrm{MHz}$ with a field strength of up to $20 \mathrm{~mW} / \mathrm{cm}^{2}$. A magnetic exposure chamber generates fields of 0 to 10 gauss, DC or $60 \mathrm{~Hz}$ (see Figure 2.23).

AC Power and Line Noise Susceptibility. Variations in power line voltage and frequency are generated over the voltage range of 0 to $125 \mathrm{~V}$ (or 0 to $250 \mathrm{~V}$ ) and in the frequency range of 20 to $2,000 \mathrm{~Hz}$. Voltage sags and surges of 0 to $\pm 5 \%$ of the power supply frequency can be generated. To simulate large transients (e.g., lightning strikes), a transient generator capable of generating ring wave and bi-wave transients meeting specifications of ANSI/IEEE C62.41 (1991) is used.

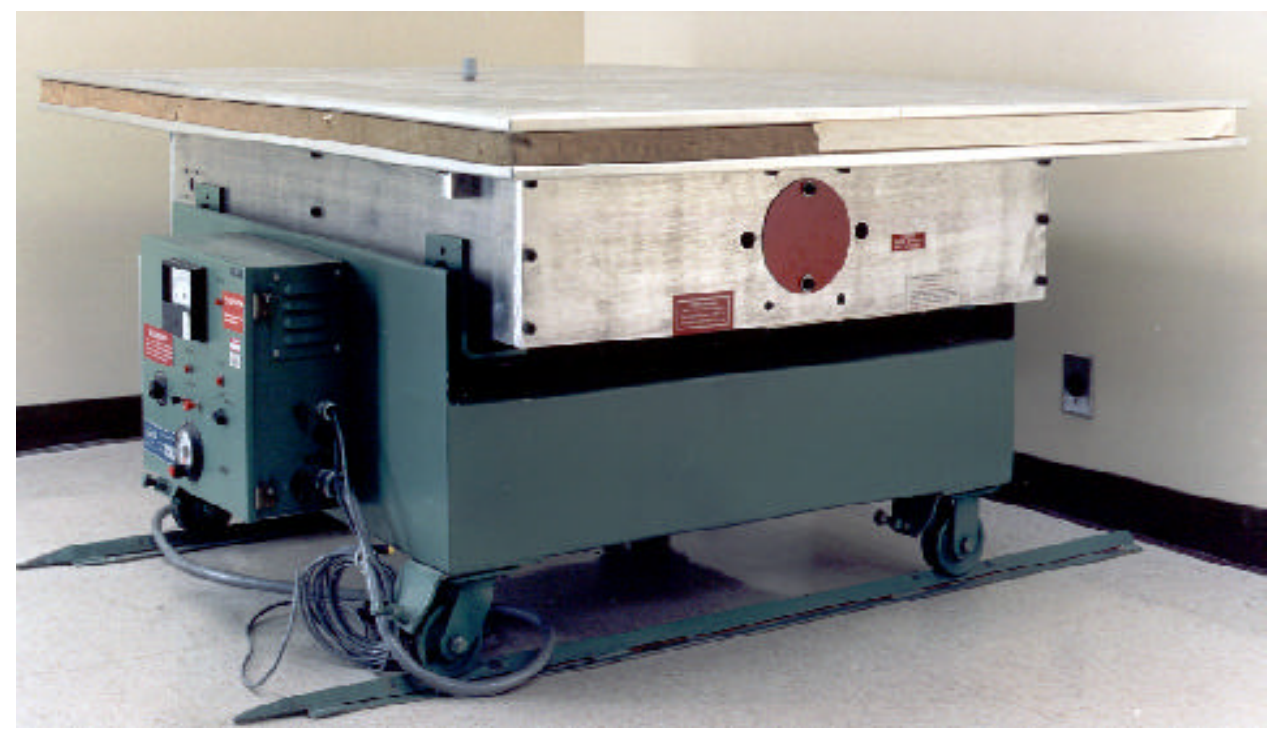

Figure 2.20. Mechanical Vibration Table (frequency range: 8 to $60 \mathrm{~Hz}$; maximum acceleration: $3.2 \mathrm{~g}$; maximum test load: $680 \mathrm{~kg}$ )

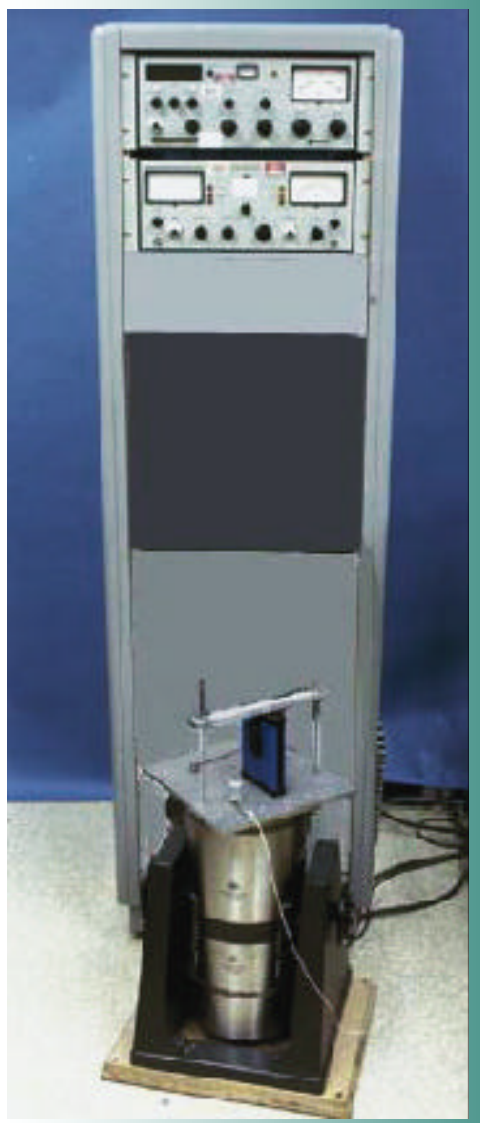

Figure 2.19. High-Frequency, High-Acceleration Vibration Table. Up to 100 lbs may be tested at up to $10 \mathrm{G}$ over the frequency range of 10 to $60 \mathrm{~Hz}$. 


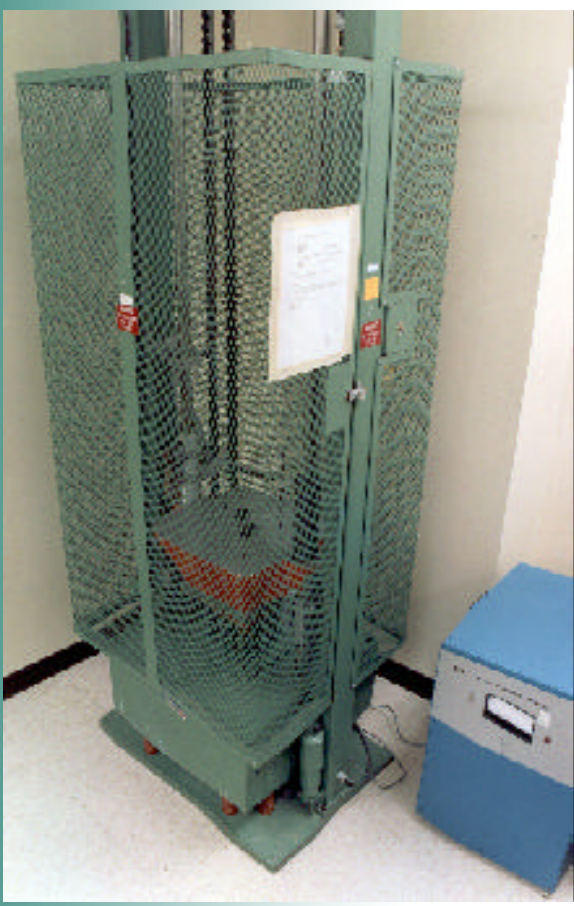

Figure 2.21. Mechanical Shock Testing Apparatus (maximum acceleration: $3000 \mathrm{G}$, maximum test load: $90.7 \mathrm{~kg}$ )

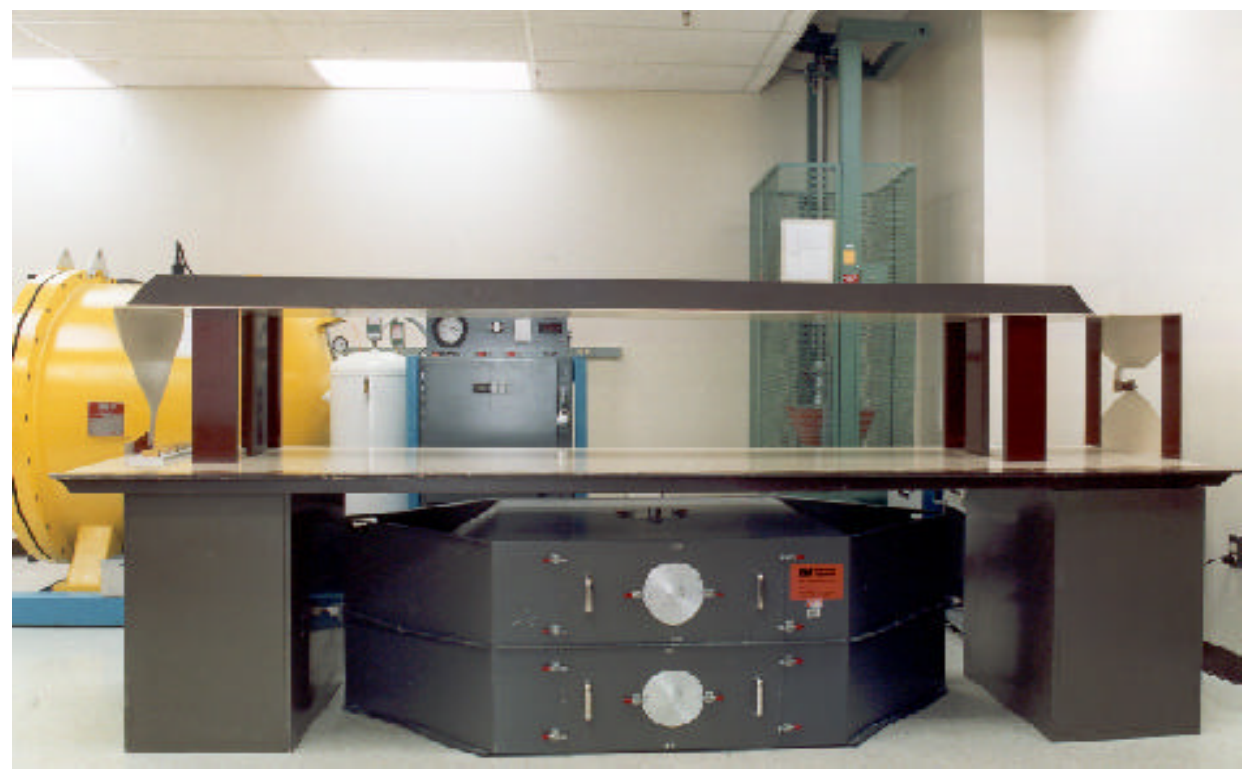

Figure 2.22. Parallel-Plate Radio Frequency Exposure System (top range: 0.3 to 35 $\mathrm{MHz}$; maximum field strength: $100 \mathrm{~V} / \mathrm{m}$ ) and Transverse Electromagnetic Cell (bottom range: $\mathrm{DC}-350 \mathrm{MHz}$; maximum field strength: $100 \mathrm{~V} / \mathrm{m}$ ).

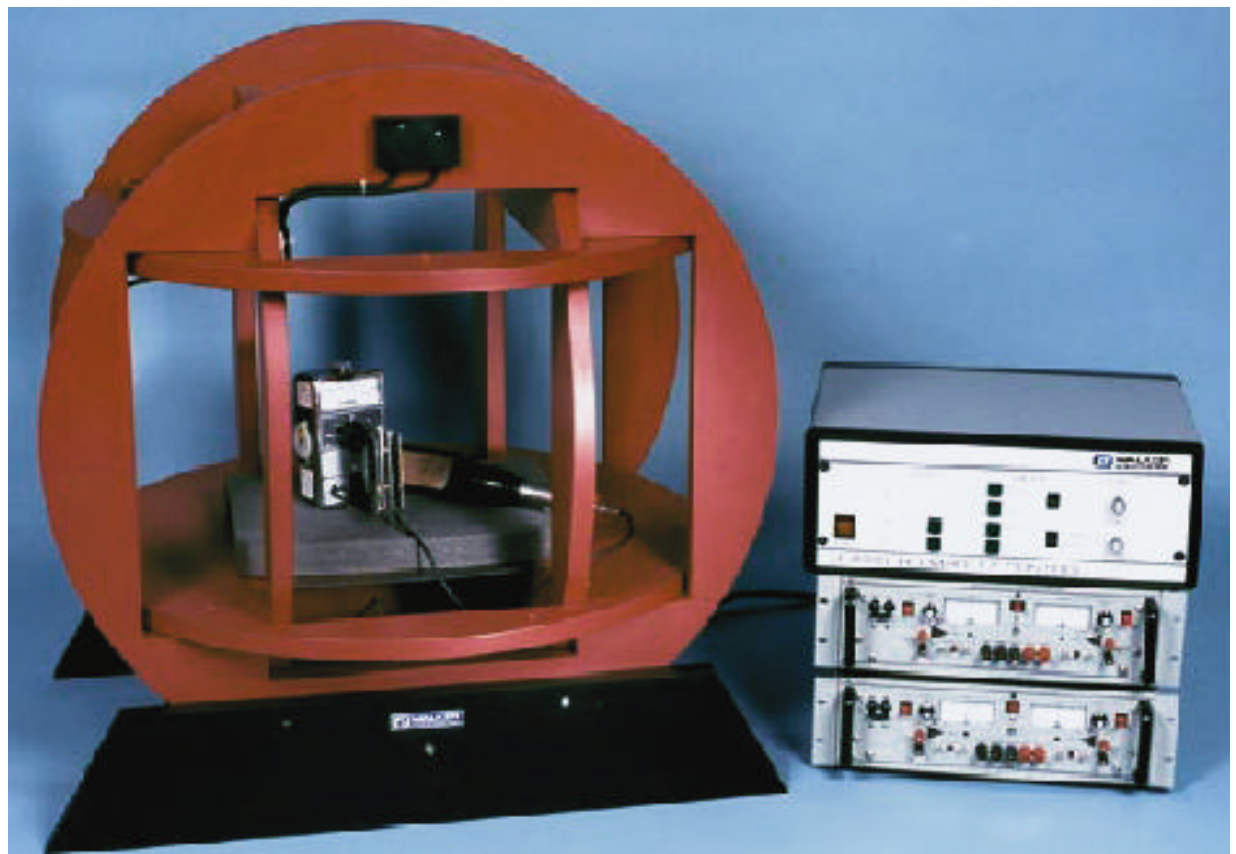

Figure 2.23. Magnetic Field Exposure System (DC and $60 \mathrm{~Hz}$; range: 0 to 10 Gauss)

\subsubsection{Instrument Repair Shop}

A complete instrument repair shop is located in the Trailer 4 addition to the calibration facility (shown in Figure 2.24) The shop is capable of housing up to six instrument repair technicians along with the equipment required to repair and maintain portable and semiportable radiological instruments. Shop capabilities also include minor machining and instrument modification. 


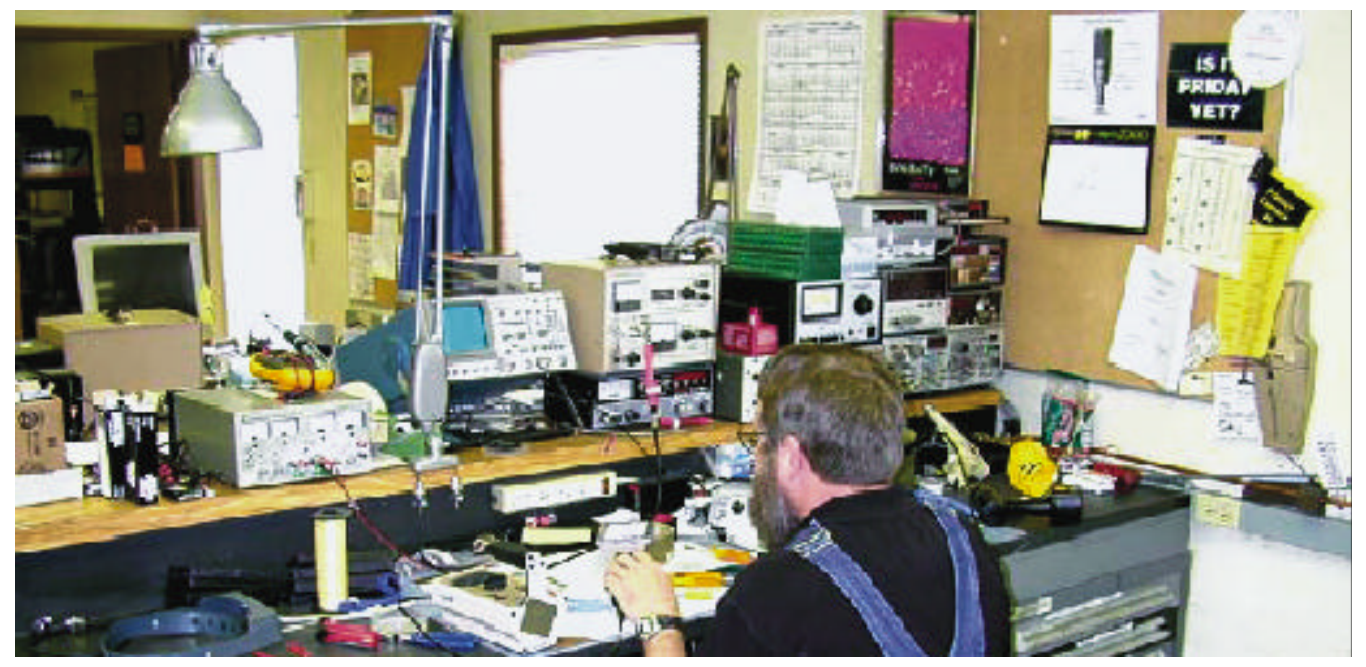

Figure 2.24. The 318 Building Radiological Calibration Facility. This facility includes an instrument repair shop that is staffed by three instrument technicians. In this photo, a technician is troubleshooting an Eberline E-600 digital ratemeter. The instrument repair shop maintains a spare parts inventory and the expertise to maintain and repair instruments calibrated by the Radiological Calibration Facility.

\subsubsection{Thermoluminescence Dosimetry Laboratory}

The External Dosimetry Program at PNNL is a large-capacity program accredited by both DOE, since the inception of DOE's Laboratory Accreditation Program (DOELAP) in 1989, and more recently accredited by the National Voluntary Laboratory Accreditation Program (NVLAP). Evaluation of thermoluminescent phosphors is routinely conducted to support the Hanford Site personnel, environmental, and nuclear accident dosimetry programs, and other DOE programs and commercial sites. The external dosimetry staff also have experience with characterizing radiation dose and depth profiles for several different laboratory sources as well as for personnel work locations. The thermoluminescence dosimetry laboratory satisfies multiple program needs for high-quality thermoluminescent dosimetry in a consistent manner.

The laboratory has several different thermoluminescent readers, including the Harshaw 8800 for beta, gamma, and neutron whole body dosimeters (Figure 2.25), the Harshaw 6600 for finger ring dosimeters (Figures 2.26 and 2.27), and Atlas "hot gas" system for reading loose thermoluminescent dosimeter (TLD) chips for special studies (Figure 2.28). The model 8800 reader is also used for the Harshaw 8807 environmental thermoluminescent dosimetry. Most types of commercially available phosphors have been processed. Glow curves are routinely monitored to ensure accurate phosphor heating and peak integration. Phosphors are annealed in an atmosphercially controlled oven for preset time and temperature conditions. Special annealing techniques are used to allow for annual exchange frequency for beta, photon, and neutron dosimeters. Laboratory lighting and temperature are regulated to minimize potential external sources of contaminants to the radiation-induced signal in the different phosphors. Dose, energy, radiation type, and environmental response characteristics have been determined for most commonly used commercial phosphors.

The laboratory has track-etch dosimetry capability for improved neutron dosimetry (Figure 2.29). Two CR39 plastic foils can be assembled in the whole body 


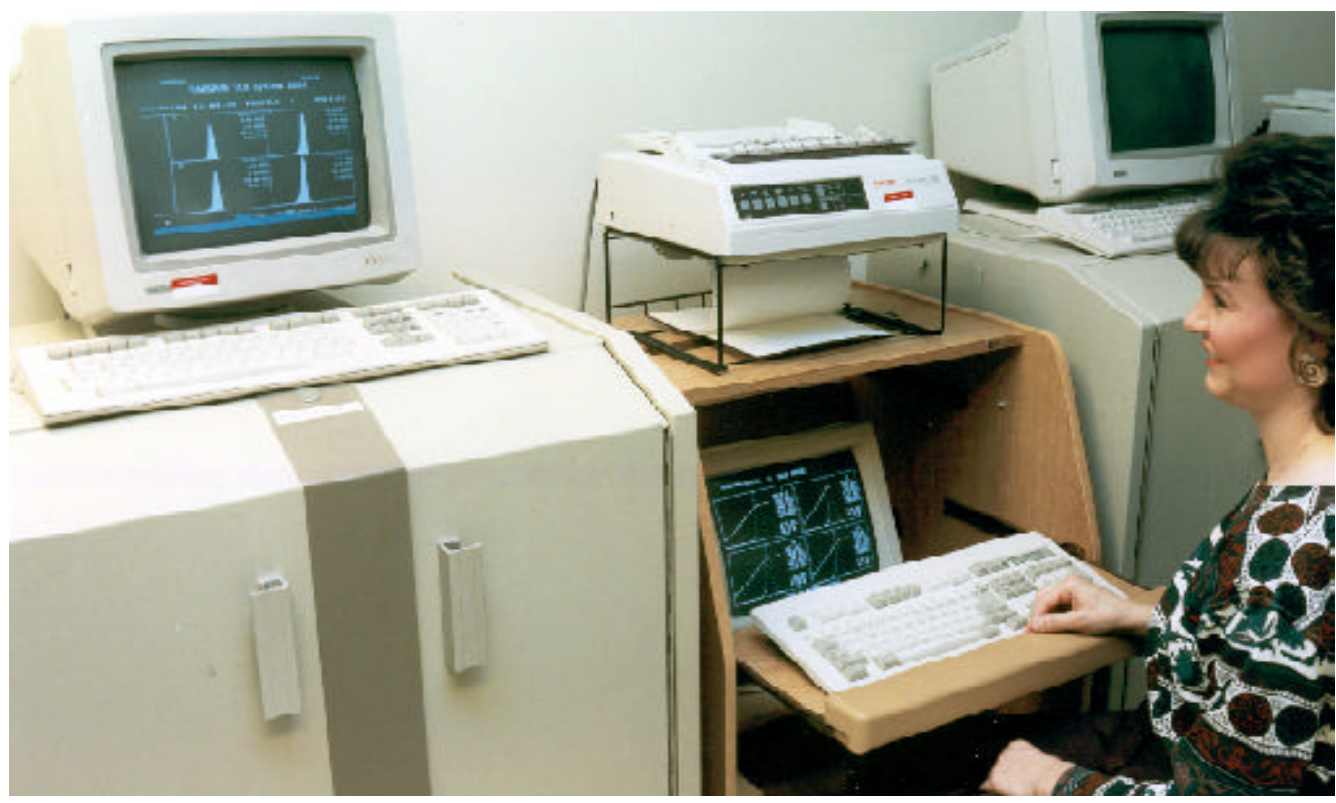

Figure 2.25. The Harshaw 8800 Reader. This system, controlled by a personal computer, processes up to 2,000 dosimeters per day. The dosimeters are "read" by heating each of the four TLD chips on the TLD card according to a programmed time-temperature profile. The light emitted from the chips is proportional to the radiation dose received and is measured with low noise photomultiplier tubes. The electronic data include 800 data points of temperature information and 800 data points of glow information for each dosimeter. Real-time process quality control is implemented through user-adjustable limits on reference light readings, photomultiplier tube noise readings, and control dosimeter readings. Any reading exceeding a limit will stop the reader.

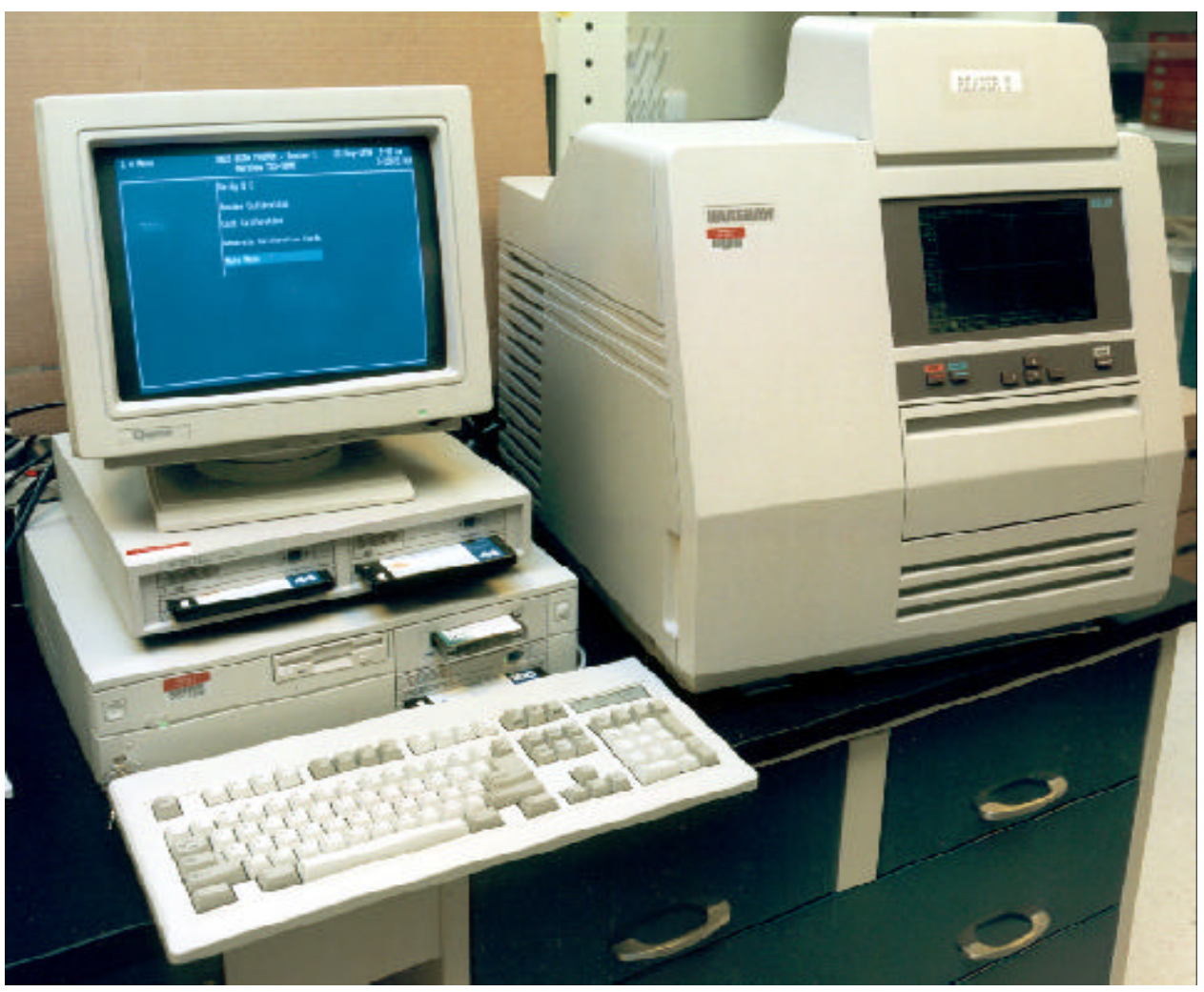

Figure 2.26. Harshaw 6600 Reader for Finger Rings. Similar to the model 8800 except that it is designed to read thinner chips used in finger rings. Operation and quality controls are similar to the model 8800 . 


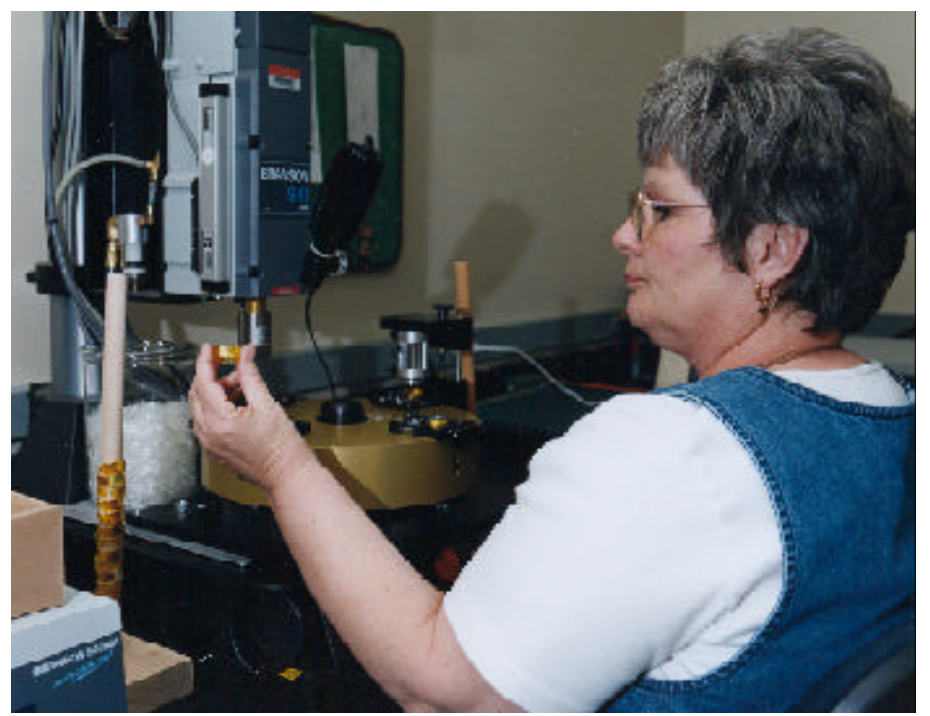

Figure 2.27. Ring Sealer. Two rings are available for use. The ICN hard plastic ring is shown being sealed for use after the single TLD chip and permanent bar code have been loaded into the ring. The Harshaw EXT-RAD is the finger ring used for nongovernment customers.

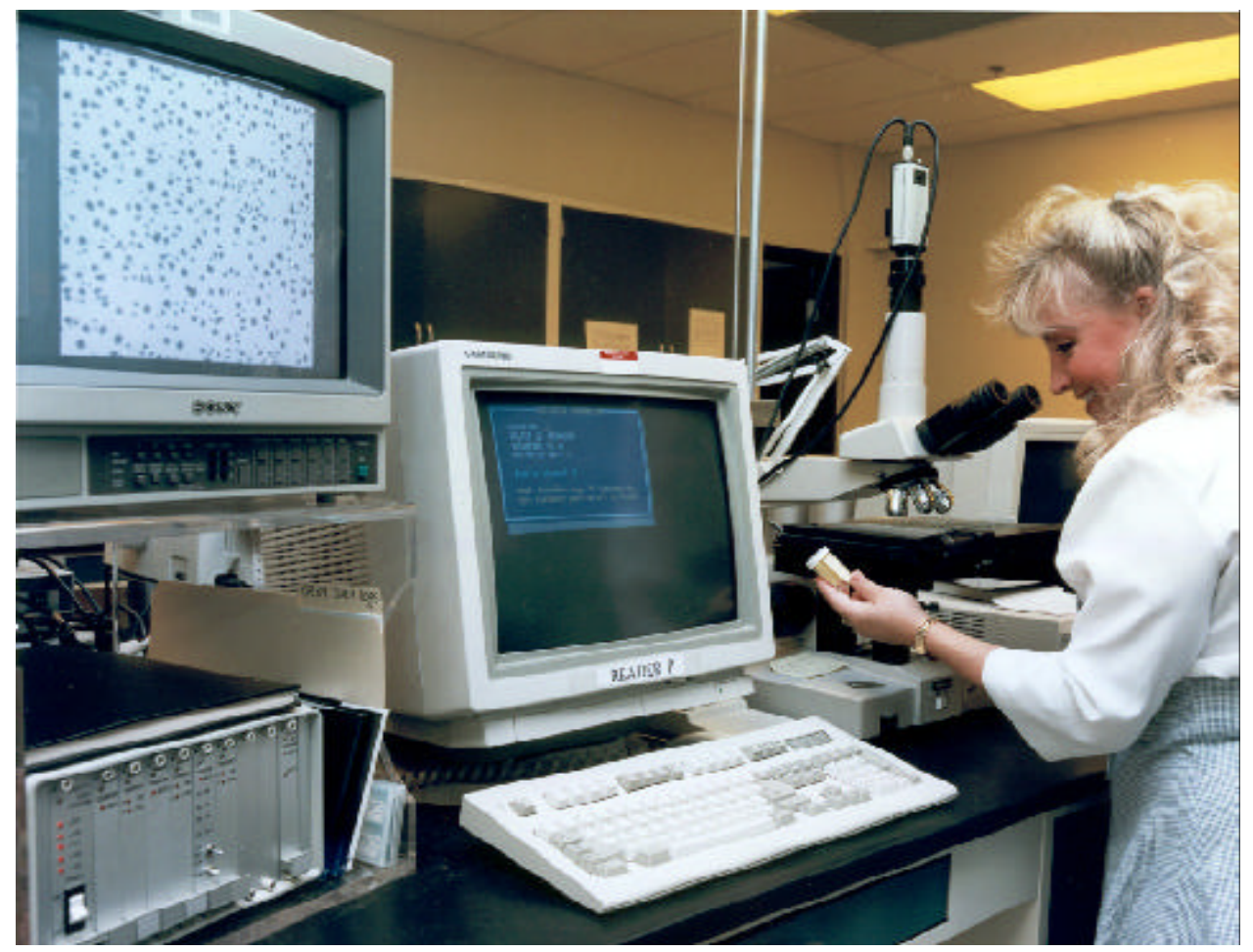

Figure 2.29. Track-Etch Dosimeter (TED) Reader. TED foils are included as one component of the Hanford combination neutron dosimeter. The foils are small sheets of CR39 polycarbonate plastic. When neutrons strike the plastic, they leave microscopic tracks. These tracks are enlarged by electro-chemical etching so that they can be counted using a microscope with a camera attached. Image-recognition software designed at Battelle "recognizes" and counts the tracks in each field of view before the automated stage moves the foil to a new position for another count. The number of tracks counted is directly proportional to the neutron dose received.

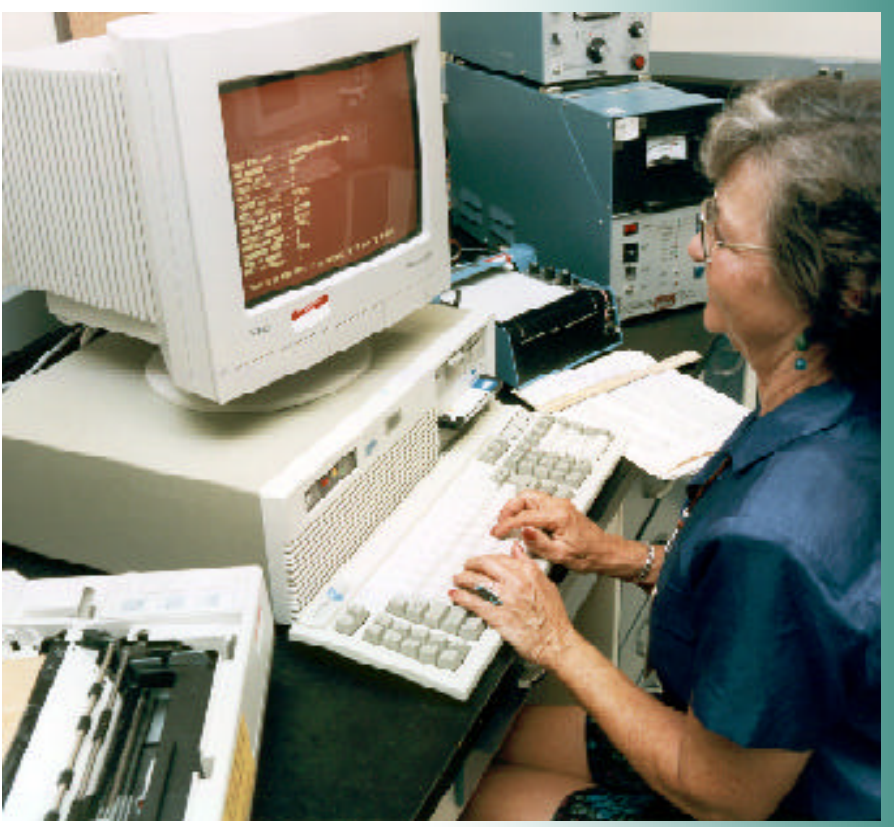

Figure 2.28. Loose Chip Reader. The ATLAS Hot Gas 2000D (in background at top right of the photo) is used to read TLD chips in the nuclear accident dosimeters and loose chips for special studies. The reader is controlled by an attendant personal computer that controls the TLD reader, collects the data, and plots the glow curves. The reader is specially calibrated for high dose (up to 10,000 R) applications. 
neutron dosimeter to supplement the neutron-sensitive TLD-600 chips. Alternatively, facility-specific neutron algorithms can be developed for use with just the TLD-600 chips, based on neutron energy characterization measurements made at a facility using tissue-equivalent proportional counters. The laboratory also provides wall-mounted nuclear accident dosimeters and personal nuclear accident dosimeters composed of a combination of TLD chips and neutron activation foils and phosphors. 


\subsection{Gamma Beam 650}

The Gamma Beam 650 (shown in Figures 3.1 and 3.2) is a ${ }^{60}$ Co irradiation unit manufactured by Atomic Energy of Canada, Limited and used in the highintensity irradiation room in the 331 Building. The facility can be used for highdose calibration and testing of dosimeters and gamma monitors (ion chambers), materials testing, biology studies, soil sterilization, and food irradiation. The pneumatically operated irradiator facilitates high dose rate cavity and panoramic irradiations. The unit consists of a single lead-filled cylindrical source head with an upper assembly of 12 source exposure tubes set in a cylindrical configuration.

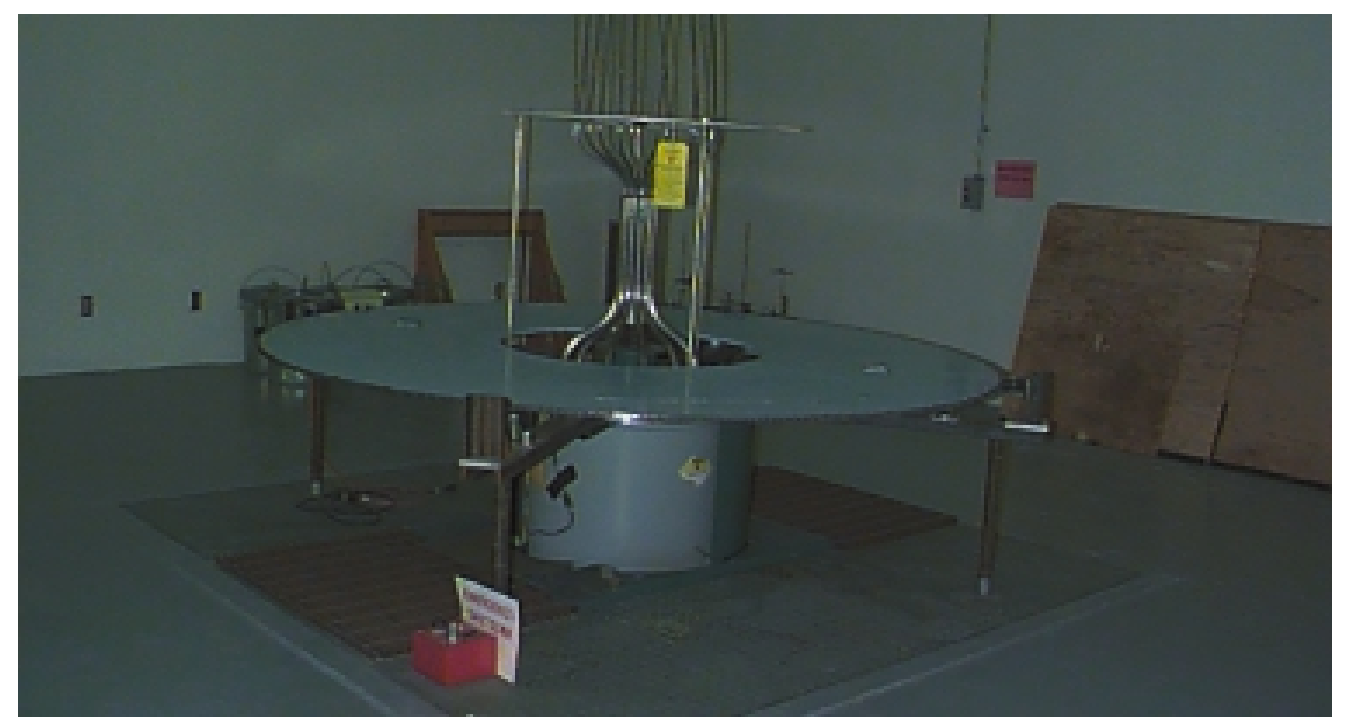

Figure 3.1. The Gamma Beam 650. This unit uses $36{ }^{60}$ Co sources to produce absorbed dose rates of up to $14 \mathrm{kGy} / \mathrm{h}$. The facility is used to evaluate the effects of radiation dose on materials and in food irradiation studies.

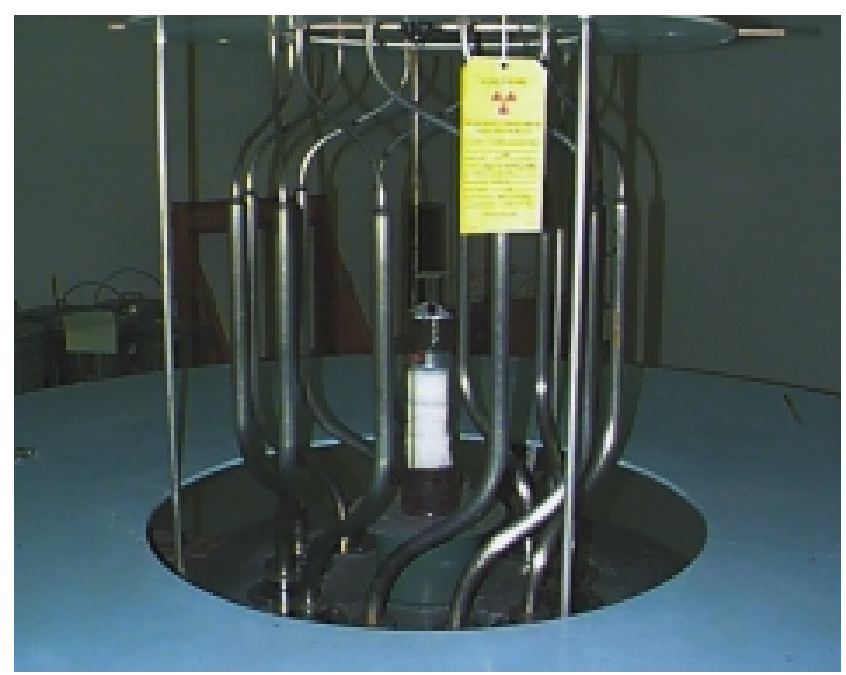

Figure 3.1. A Close Up of the 12 Source Tubes in the Gamma Beam 650. To adjust the absorbed dose rate, the tubes are rotated about their vertical axis to be closer or further from the test object. By altering the number of sources in each, the number of tubes used, and the distance between the tubes and the test object, uniform fields of $0.1 \mathrm{~Gy} / \mathrm{h}$ to $14 \mathrm{kGy} / \mathrm{h}$ can be generated. 
Sample materials can be irradiated either centrally on a platform located at the center of the exposure tube assembly or panoramically by positioning the sample material in the air space around the unit. The total source strength of the combined ${ }^{60} \mathrm{Co}$ sources is roughly $20,000 \mathrm{Ci}$ (1994), and the reference dose rate at the center of the tube assembly with all sources exposed is roughly $1.4 \mathrm{Mrad} / \mathrm{h}$ (2001). 


\subsection{Non-Destructive Analysis Laboratory}

The PNNL Non-Destructive Analysis (NDA) Laboratory conducts waste characterization measurements on a variety of waste containers, including 55-gallon drums, 4-ft x 4-ft x 8-ft metal and wood boxes, and various spent fuel and nuclear material storage casks. NDA counting equipment is also used to measure and quantify facility holdup in process piping, ductwork, high-efficiency particulate air (HEPA) filters, fume hoods, and gloveboxes. State-of-the-art neutron coincidence counters are used to support the annual International Atomic Energy Agency (IAEA) verification activities at the Hanford Site. In the past, a combination of measurements and calculations has been used to determine the radionuclide inventory in reactor control rods, vitrified waste logs, and Mark 42 fuel assemblies. A mobile NDA Laboratory is used for offsite waste characterization activities.

Analysis equipment available to perform the above activities includes the following:

\section{$\checkmark$ Segmented Gamma-Scan Neutron Assay}

System. This system (see Figure 4.1) is an automated NDA neutron/gamma counter system used to characterize the types and amounts of low-level or transuranic (TRU) waste. PNNL's NDA laboratory participates in the NDA portion of the Performance Demonstration Program for the Waste Isolation Pilot Plant TRU Waste Characterization Program initiated in September 1997.

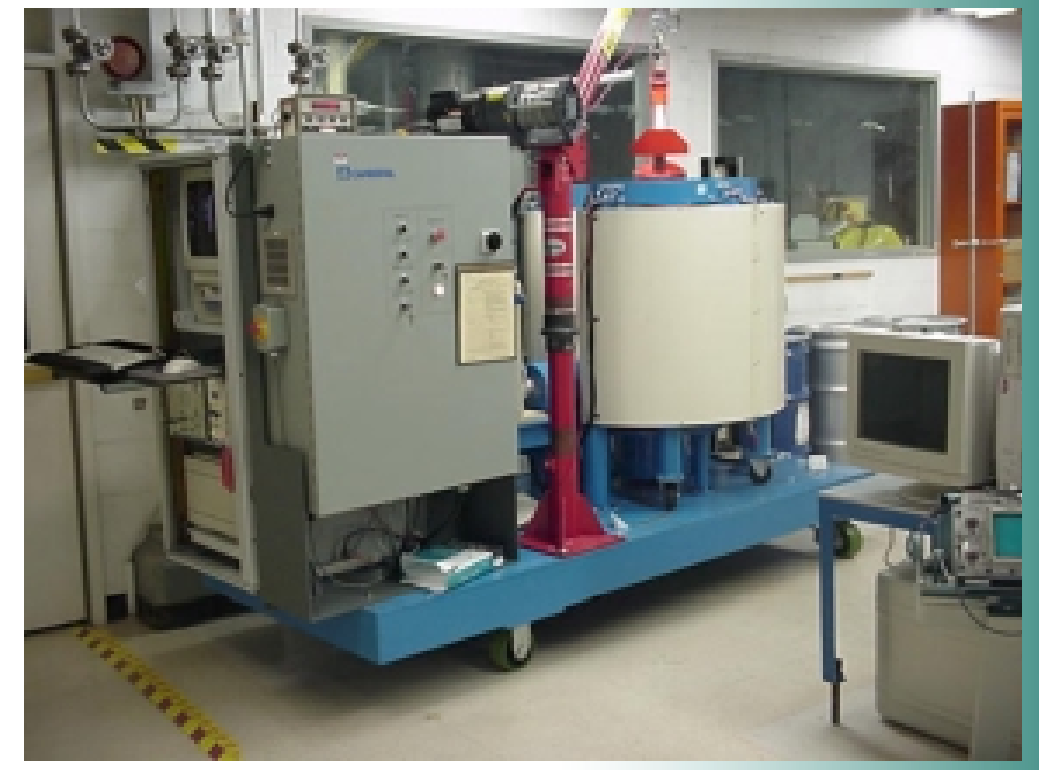

Figure 4.1. Segmented Gamma-Scan Neutron Assay System

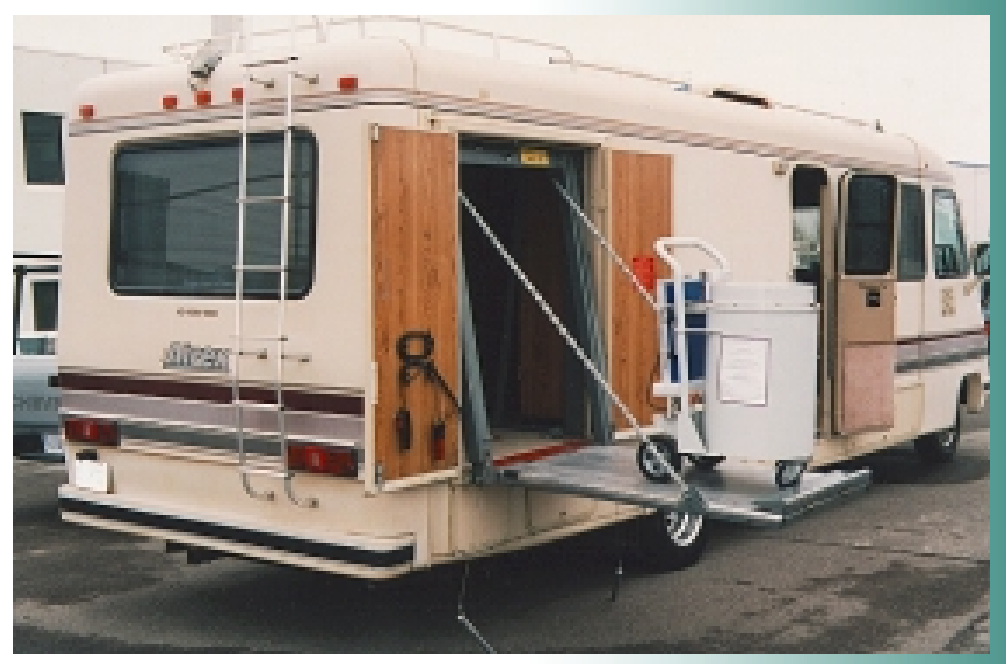

Figure 4.2. Mobile Non-Destructive Assay Laboratory $\checkmark$ Mobile NDA Laboratory. This mobile laboratory (see Figure 4.2) is a converted commercially available 28-foot Airex motorhome. It has been modified to provide a lift mechanism for loading/unloading NDA equipment and is selfcontained with onboard electrical, heating, and air-conditioning systems. It has been used as a mobile laboratory and for delivery of NDA assay equipment to onsite/offsite measurement locations. The uses for this mobile laboratory include the verification measurements of TRU inventories, material control and accountability for safeguards, TRU and low-level waste characterization of contact-handled drums and holdup measurements in support of decontamination 


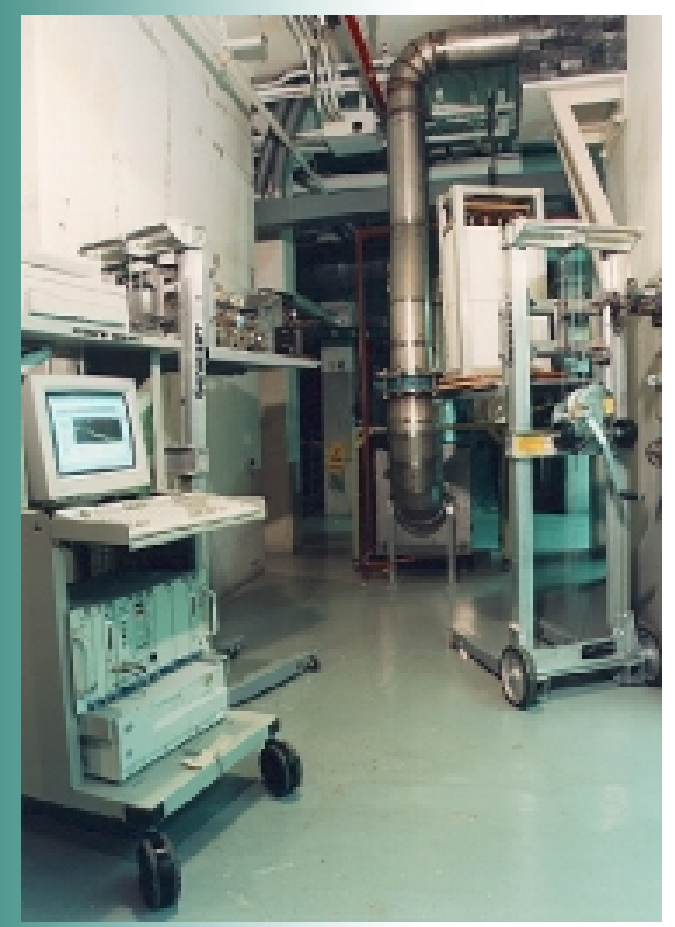

Figure 4.3. Holdup Measurement Setup. It includes a HPGe detector and a slab neutron detector. and decommissioning efforts, and backup emergency mobile laboratory for DOE Region 8 emergency response. The equipment housed in this mobile laboratory includes the following:

- a transportable Mound Laboratory over/under calorimeter with a capacity of two sample cells with 2500 grams plutonium per cell

- a portable Jomar high-level neutron coincidence counting/active well coincidence counting system

- a portable isotopic assay system with a high-purity germanium (HPGe) planar detector and the MGAPC software developed by Lawrence Livermore National Laboratory

- a transportable segmented gamma-scanning neutron assay system for 55-gallon drums

- radioactive material holdup measurement equipment, including an HPGe detector and a slab neutron detector (Figure 4.3). 


\subsection{In Vivo Radioassay and Research Facility}

The In Vivo Radioassay and Research Facility (IVRRF) located in Richland, Washington, is designed expressly for the measurement and quantification of radioactive material in the body ${ }^{(a)}$.

The majority of the work at IVRRF involves measurements of Hanford radiation workers under the auspices of the In Vivo Monitoring Program (IVMP) for Hanford. However, work is also performed for non-DOE clients as Battelle, Pacific Northwest Division.

\subsection{In Vivo Counting Facilities}

Each of the in vivo counting systems is housed in a heavily shielded room to reduce the environmental background radiation levels. Three rooms are shielded with steel from the hulls of decommissioned battleships. Thin layers of lead, cadmium or tin, and copper or stainless steel shielding are also used on the interior walls of the rooms to reduce the background from low energy photons primarily generated from the absorption of high energy cosmic radiations in the steel. Two other counting systems are shielded with lead. Table 5.1 contains minimum detectable activities for these systems.

Table 5.1. Typical Minimum Detectable Activities (MDA)

\begin{tabular}{|l|c|}
\hline \multicolumn{1}{|c|}{ Nuclide } & MDA (nCi) \\
\hline 50-min Chest Count & \\
\hline${ }^{241} \mathrm{Am}$ & 0.15 \\
\hline${ }^{234} \mathrm{Th}$ & 1.5 \\
\hline${ }^{235} \mathrm{U}$ & 0.09 \\
\hline 3-min Standup Whole Body Count & \\
\hline${ }^{137} \mathrm{Cs}$ & 1.3 \\
\hline $\mathbf{1 0}$-min Coaxial Germanium & \\
Whole Body Count & 0.80 \\
\hline${ }^{137} \mathrm{Cs}$ & 1.7 \\
\hline${ }^{154} \mathrm{Eu}$ & \\
\hline
\end{tabular}

There are four routinely used counting systems and several less frequently used systems. The two primary whole body counting systems are designed to detect and quantify radionuclides (e.g., ${ }^{137} \mathrm{Cs},{ }^{60} \mathrm{Co}$, and ${ }^{154} \mathrm{Eu}$ ) that emit photons with energies greater than $200 \mathrm{keV}$. One whole body counting system uses an array of 5 large $\mathrm{NaI}$ detectors and is used as a screening counter. The other system is a scanning arrangement that employs seven coaxial HPGe detectors. 


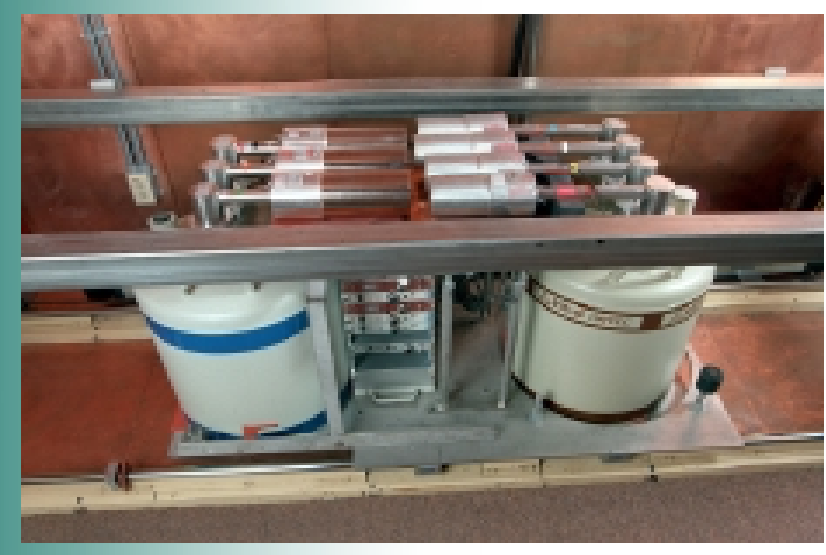

Figure 5.1. Coaxial High-Purity Germanium Detectors in Palmer Room

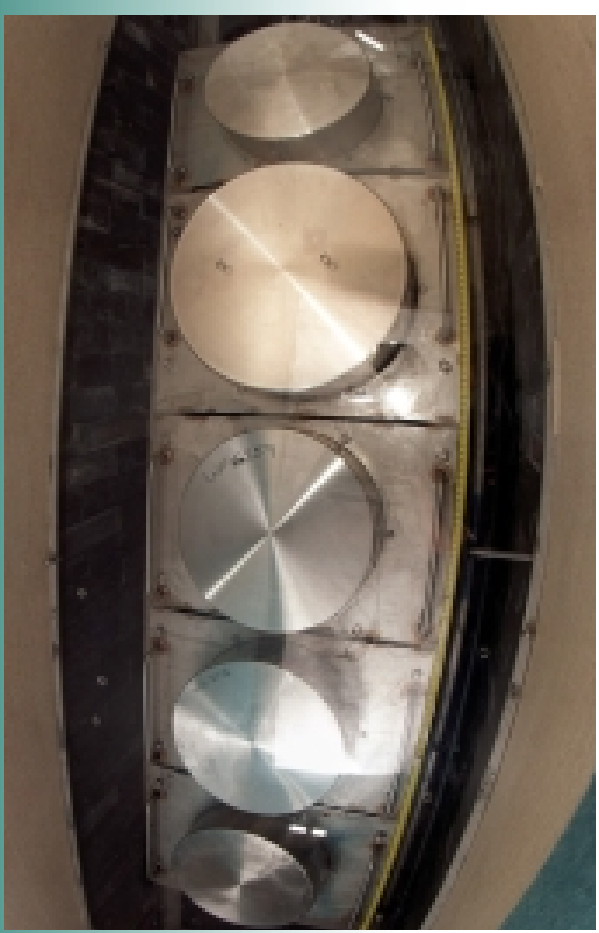

Figure 5.2. Standup Counter Detectors

The Palmer Room measures 2.5 x 3.7 × $2.4 \mathrm{~m}(8.3 \times 12 \times 8$ $\mathrm{ft}$ ), with the walls, floor, and ceiling being made of $30-\mathrm{cm}$ (12-in.) battleship armor plate, from the U.S.S. Indiana, lined on the inside with a graded shield composed of thin layers of lead, cadmium, and copper. A seven-detector array of large-volume coaxial germanium detectors is installed in the room for whole body measurement of gamma ray energies above $200 \mathrm{keV}$. The system can be operated in a stationary or a scanning mode.

(See Figure 5.1)

The standup counter (Figure 5.2), like the lead room (discussed below), is shielded with 10-cm- (4-in.) thick virgin lead brick and is designed for a subject to stand upright and have a quick measurement performed. The counter has a shielded maze entrance that prevents unscattered photons not coming from the subject from reaching the detectors. This counter is used to perform screening measurements; more precise measurements are made with HPGe detection systems.

The two lung counting systems are comprised of similar arrays of four $38-\mathrm{cm}^{2}$ planar germanium detectors and associated electronics. Their design optimizes the detection efficiency for measurement of lowenergy photons $(<200 \mathrm{keV})$ emitted by radionuclides such as ${ }^{239} \mathrm{Pu}$, ${ }^{241} \mathrm{Am}$, ${ }^{\text {nat }} \mathrm{U}$, and ${ }^{235} \mathrm{U}$. The lung counting systems are housed in the Iron Room and the Stainless Steel room.

The Iron Room measures 2.7 × 3.0 × 2.3 m $(8.9$ x 9.8 x $7.3 \mathrm{ft})$, having 25.4-cm- (10-in.-) thick hardened iron armor plate walls, ceiling, and floor. An array of four planar germanium detectors is installed in this room to measure plutonium, americium, uranium, and other low-energy photon-emitters. The inner lining of the room consists of a graded shield of 3.2-mm (0.125-in.) lead, 0.5-mm cadmium, and $1.5-\mathrm{mm}$ copper to further reduce the background scattered radiation at low energies. (see Figure 5.3)

The Stainless Steel room measures $2.9 \mathrm{~m}$ x $3.0 \times 2.2 \mathrm{~m}(9.5 \times 10 \times 7.25$

$\mathrm{ft}$ ). It has common walls with two other shielded rooms. It has a $30-\mathrm{cm}$ (12-in.) thick iron wall in common with the Palmer Room, a 25.4-cm (10-in.) thick iron wall in common with the iron room, and two iron walls $19-\mathrm{cm}$ (7.5-in.) thick that were obtained from the Nevada Test Site. The floor and ceiling are composed of $12.5-\mathrm{cm}(5-\mathrm{in}$.) thick iron armor plate and 10-cm (4-in.) of lead brick. This room has a graded shield of .318-cm (.125-in.) lead, 0.159-cm (.0625-in.) tin, and 0.159-cm (.0625-in.) stainless steel, the tin replacing cadmium for cost purposes, and the stainless steel replacing copper for its better wear properties. Background measurements taken in the room indicated that this type of shielding was equivalent to the iron room shielding. (see Figure 5.4) 
A fifth room, the lead room, has 10-cm(4-in.-) thick lead walls, ceiling, and floor composed of virgin lead bricks that are covered by a $1.0-\mathrm{mm}$ layer of copper. The room is $2.85-\mathrm{m}$ long $\mathrm{x} 2.34-\mathrm{m}$ wide $\mathrm{x} 2.08-\mathrm{m}$ high (9-ft 4-in. x 7-ft 8-in. x 6-ft-10 in.). Arrays of planar germanium detectors are used in this room to measure transuranic, uranium, and other low-energy photon-emitters. Arrays of sodium iodide detectors can be configured in a bed arrangement for measurement of highenergy photons.

\subsection{Calibration Phantoms}

Anthropomorphic phantoms are used to calibrate the counting systems in order to obtain an accurate estimate of the activity in the workers. Several torso phantoms are available to provide detailed simulation of the body dimensions from the shoulders to the hips. The phantom composition closely simulates the radiation interaction properties of the tissues in the body for energies as low as $17 \mathrm{keV}$. The torso phantoms include overlays that allow calibration factors to be determined for a variety of tissue thickness over the lungs (Figure 5.5).

Whole body, lung, liver, thyroid, bone, and wound phantoms are available that contain known amounts of radioactive material. Lung phantoms that contain the radioactive material are inserted in the torso phantoms for calibration measurements on the lung-counting systems. Bottle manikin absorption (BOMAB) phantoms (Figure 5.6) contain radioactive material uniformly distributed throughout the tissue-substitute material and are used to calibrate the whole body counting systems. The other phantoms are used, as needed, to establish proper calibrations. ${ }^{(a)}$ The phantoms are part of the DOE Phantom Library and are available for loan to other in vivo counting facilities.

(a) A complete list of phantoms and descriptions can be found at http:/www.pnl.gov/phantom/.

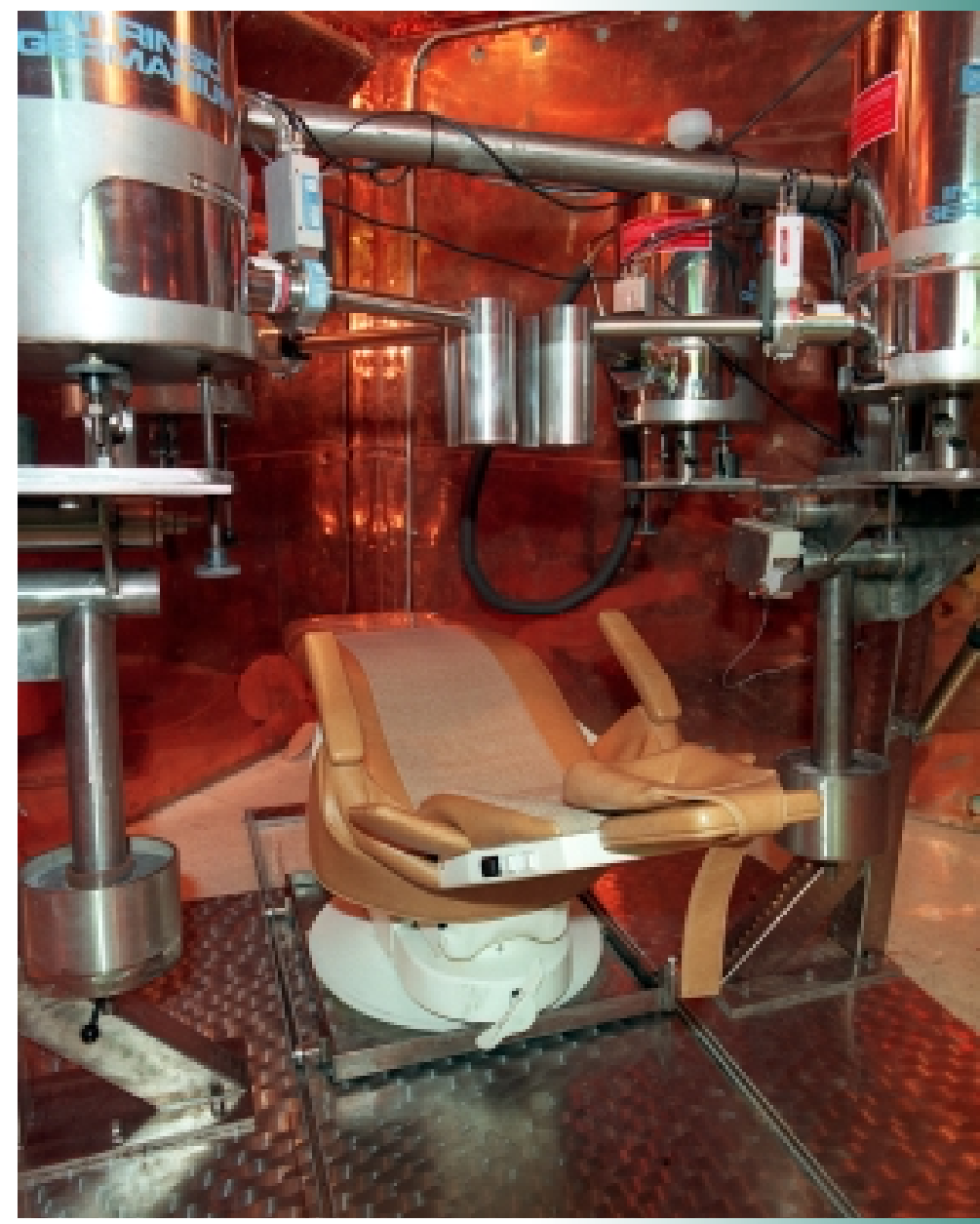

Figure 5.3. Iron Room Counting System

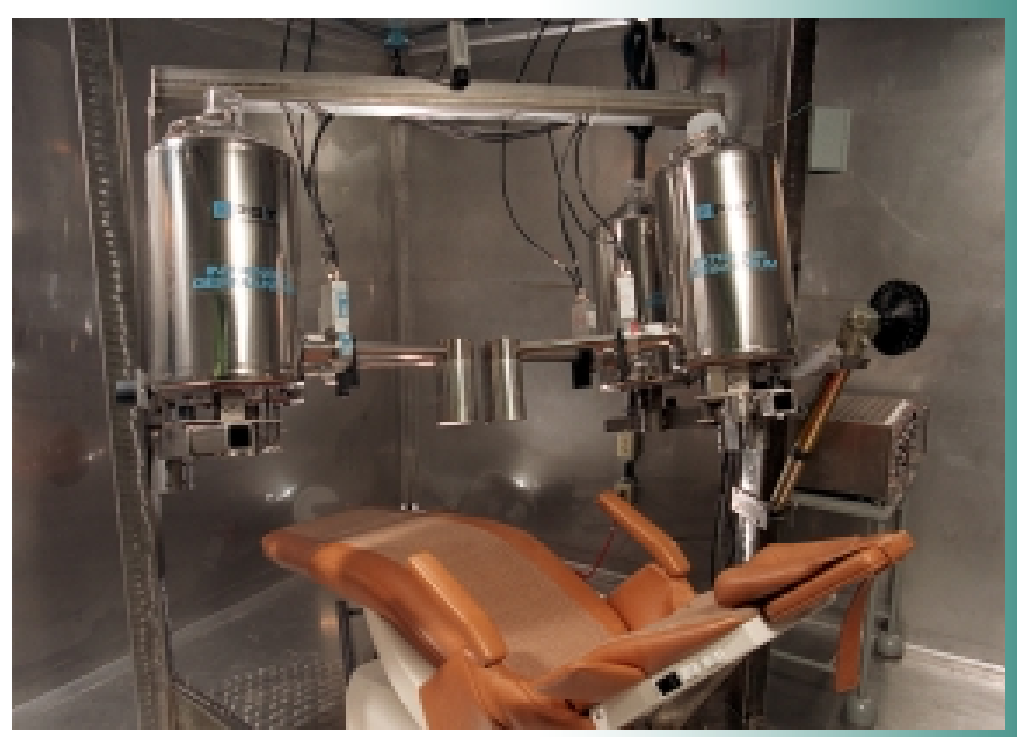

Figure 5.4. Stainless Steel Room Counting System 


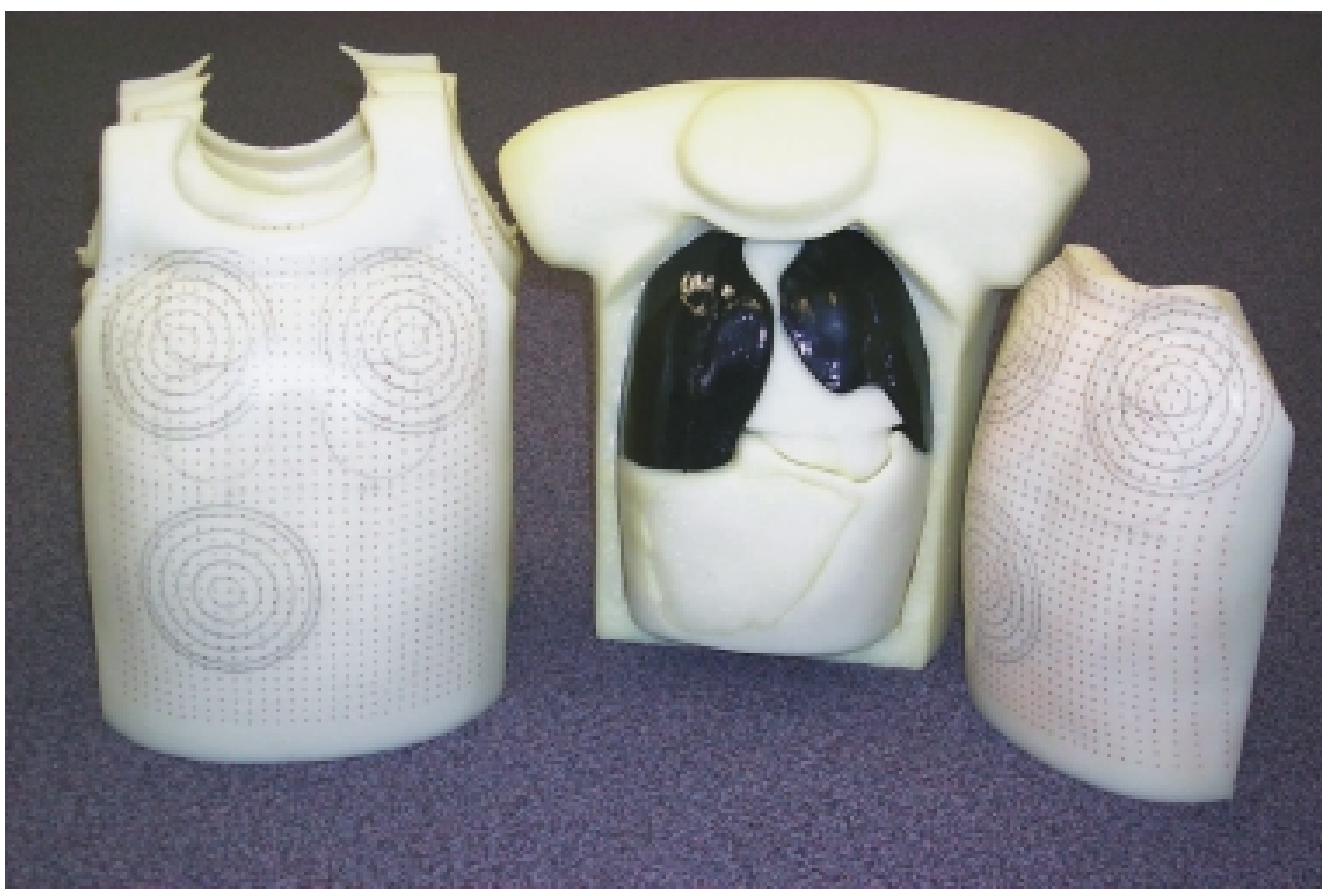

Figure 5.5. Torso Calibration Phantom

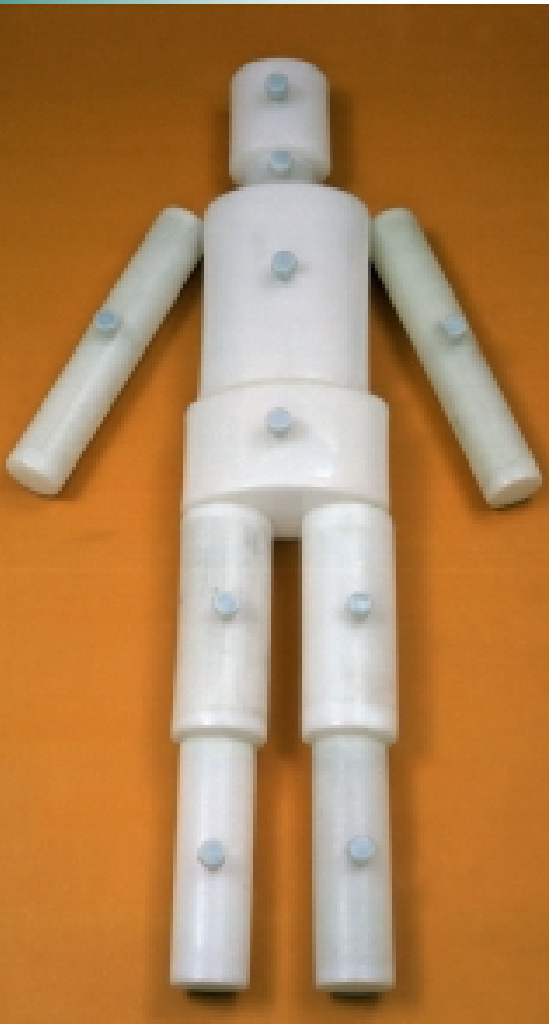

Figure 5.6. Bottle Manikin Absorption Phantom
Staff conduct research and development on tissue substitute materials and calibration phantoms for in vivo bioassay at the Research Technology Laboratory located near the IVRRF. Unique tissue-substitutes are fomulated to have attenuation coefficients modeled after values published in International Commission on Radiation Units and measurements. Publications 44 and 48 (ICRU 1989; 1992). The tissue substitute materials are formed into simulated tissues and organs that contain radioactive materials in a uniform distribution. Solid tissue substitutes are available for calibrations of equipment and include lung phantoms for the Realistic Torso phantom; lung phantoms for the JAERI Torso phantom; whole body BOMAB phantoms; and organ phantoms including liver, skeletal, thyroid, and lymph nodes. The laboratory also provides the calibration lung phantoms for the DOELAP for radiobioassay and has provided many government and private customers with customized calibration phantom applications. 


\subsection{Laboratory Standards and Traceability Program}

The RS\&CL is charged with maintaining traceability of local radiological standards to appropriate national standards. In December 1993, the Calibration Research and Accreditation (CR\&A) group, a section of the Dosimetry Research and Technology technical unit, achieved accreditation as a Calibration Laboratory for Ionizing Radiation (CLIR) through the NIST/NVLAP. This accreditation implies concurrence by NIST $^{(a)}$ that CR\&A has the ability to provide and maintain highly accurate radiological reference fields commensurate with the recommendations of NIST Special Publication 812 (DOC/NIST 1991) and the ISO and ANSI quality and adminstrative requirements as interpreted by the NVLAP Handbook 150 , and is knowledgeable in the application of these reference fields to the calibration and/or irradiation of active and passive detection devices. Furthermore, the accreditation documents compliance of the CR\&A group, as suppliers of calibration or test results, with criteria established in Title 15, Part 285 Code of Federal Regulations, which encompass the requirements of ISO/IEC Guide 25 (1990) and the relevant requirements of ISO 9002 (1987).

In its role to maintain NVLAP accreditation and traceability to national standards, the CR\&A group is the custodian of various radiological secondary (transfer) standards that have been calibrated directly by NIST or a national standards agency of another country. The CR\&A group uses these standards to establish and maintain selected tertiary and working standards used within the RS\&CL, including those reserved specifically for survey instrument calibrations (e.g., well-geometry sources). This arrangement does not extend actual or implied NVLAP accreditation for the users of calibrated reference fields outside of the CR\&A group; however, it provides confidence in the quality of the reference fields, with the knowledge that they have been established using the same protocols applied for accredited capabilities.

\subsection{Quality Assurance Program}

Quality assurance (QA) is defined as planned and systematic actions necessary to provide adequate confidence that an item or facility will perform satisfactorily in service. Establishing and implementing a QA program in conformance with 10 CFR 830.120 is essential. All measurement and test equipment is assigned a calibration level: Level 1 is assigned to local standards calibrated by qualified standards or neutral laboratories, such as NIST; Level 2 is assigned to equipment calibrated in-house using the Level 1 equipment and to tasks where it is necessary to establish traceability of the final measurement; Level 3 is assigned to equipment used for indication only.

(a) Although this accreditation is established through NVLAP, it in no way constitutes or implies certification, approval, or endorsement by NIST of the products calibrated, irradiated, or tested. 
In addition, several major programs use QA coordinators to ensure that special needs are met. Training and retraining programs have been established for project workers. Work procedures are prepared when appropriate and are available to project workers. Certification of traceability for Level 1 equipment is maintained on file. A QA support system provides for the routine use of M\&TE, such as beam monitors, laser-alignment equipment, automatic timers, and datalogger/process-control computers that are required for facility calibration work. Documentation and record keeping are extensive and are considered important components of the QA program.

\subsection{Local Standards and Traceability Program}

Maintaining radiological reference fields traceable to national standards is a primary goal of PNNL programs. Traceability means adopting some method of ensuring that calibration fields are established and used consistently with national standards. Two acceptable consistency measurements are commonly used to infer traceability: 1) implied consistency, which is established through the use of a laboratory standard submitted to NIST for calibration within radiation fields applicable to the laboratory, and 2) demonstrated consistency, which is established through a measurement quality assurance (MQA) interaction with NIST. This latter method is akin to a performance test administrated by NIST and is instrumental in verifying measurement traceability, as opposed to simply obtaining or maintaining a traceable source or reference instrument (i.e., artifact traceability). The disadvantage of traceability based only on implied consistency is the lack of demonstration; demonstration would indicate that measurements made of traceable sources or using traceable reference instruments are consistent with those made using national standards. Traceability based on demonstrated consistency provides some assurance that traceable instruments and/or sources are being used properly - whether it be to calibrate additional sources (or reference fields) or laboratory instrument standards - such that traceability is appropriately extended as desired.

The NIST supports the use of both techniques in maintaining traceability, but favors the practice of performing MQA interactions on a routine basis coupled with providing infrequent instrument or source calibrations. The RS\&CL has adopted the NIST philosophy and has sought to implement it whenever possible.

\subsection{Calibration Uncertainties}

The uncertainties associated with 1) the dose rates of reference standard fields, 2) the calibration of reference standard instruments and, 3) the final values associated with the calibration of dosimeters and survey instruments, are calculated using the methodology in NIST Technical Note 1297 (NIST 1994) and the ISO Guide to the Expression of Uncertainty in Measurement (1993). This methodology breaks both random and systematic uncertainties into two types:

$\checkmark$ Type A: those that are evaluated by applying statistical methods to a series of repeated determinations

Type B: those that are evaluated by other means. 
The combined standard uncertainty of a measurement is obtained by combining the associated individual standard uncertainties of both Type A and Type B by the usual method. This usual method is called the law of propagation of uncertainty, and is based on the Taylor series expansion. Most calculations for the combined uncertainty involve the quadratic sum of the individual uncertainties. To arrive at the total expanded uncertainty of a quantity and its associated confidence level, the combined uncertainty (in the form of one standard deviation or equivalent) is multiplied by the appropriate coverage factor (based on the number of degrees of freedom).

Irradiations and/or calibrations performed within the scope of PNNL's NVLAP accreditation are reported complete with estimates of the expanded uncertainty using this method. When significant improvement in the measurement uncertainty is desired, PNNL may perform additional evaluations of the irradiated or calibrated artifacts to refine particular components of the uncertainty. PNNL staff may also recommend and/or assist the end user of the calibrated equipment in determining test methods that allow for the correct propagation of uncertainties through the user's site-specific application of the $\operatorname{artifact}(\mathrm{s})$. 


\subsection{References}

10 CFR 830.120. Code of Federal Regulations, Title 10, Energy, Part 835.120, "Energy/Nuclear Safety Management/Quality Assurance Requirements."

10 CFR 835. Code of Federal Regulations, Title 10, Energy, Part 835, "Occupational Radiation Protection."

15 CFR 285. Code of Federal Regulations, Title 15, Commerce and Foreign Travel, Part 285, "National Voluntary Laboratory Accreditation Program Procedures and General Requirements."

American National Standards Institute (ANSI). 1994. American National Standard for Calibration - Calibration Laboratories and Measuring and Test Equipment - General Requirements. ANSI/NCSL Z540-1, New York.

American National Standards Institute (ANSI). 1993. American National Standard for Dosimetry - Personnel Dosimetry Performance - Criteria for Testing. ANSI N13.11, New York.

American National Standards Institute/Institute of Electrical and Electronics Engineers, Inc., (ANSI/IEEE). 1991. IEEE Recommended Practice on Surge Voltages in Low-Voltage AC Power Circuits. ANSI/IEEE C62.41, published by IEEE, New York.

American National Standards Institute (ANSI). 1989a. Performance Specifications for Health Physics Instrumentation - Portable Instrumentation for Use in Normal Environmental Conditions. ANSI N42.17A, New York.

American National Standards Institute (ANSI). 1989b. Performance Specification for Health Physics Instrumentation - Portable Instrumentation for Use in Extreme Environmental Conditions. ANSI N42.17C, New York.

International Commission on Radiation Units and Measurements (ICRU). 1989. Tissue Substitutes in Radiation Dosimetry and Measurement. ICRU Report 44, Bethesda, Maryland.

International Commission on Radiation Units and Measurements (ICRU). 1992. Phantoms and Computational Models in Therapy, Diagnosis, and Protection. ICRU Report 48, Bethesda, Maryland.

International Standards Organization (ISO). 2001. Reference Neutron Radiations - Part 1: Characteristics and Methods of Production. ISO 8529-1, Geneva, Switzerland.

International Standards Organization (ISO). 1996. X and Gamma Radiation for Calibrating Dosemeters and Doserate Meters and for Determining Their Responses as a Function of Photon Energy - Part 1: Radiation Characteristics and Production Methods. ISO 4037-1, Geneva, Switzerland. 
International Standards Organization (ISO). 1993. Guide to the Expression of Uncertainty in Measurement. Geneva, Switzerland.

International Standards Organization (ISO). 1990. General Requirements for the Competence of Calibration and Testing Laboratories. ISO/IEC Guide 25, Third edition, Geneva, Switzerland.

International Standards Organization (ISO). 1987. Quality Systems - Model for Quality Assurance in Production and Installation. ISO 9002, Geneva, Switzerland.

International Standards Organization (ISO). 1984. Reference Beta Radiations for Calibrating Dosemeters and Doserate Meters and for Determining Their Response as a Function of Beta Radiation Energy. ISO 6980, First edition, Geneva, Switzerland.

National Institute of Standards and Technology (NIST). 1994. National Voluntary Laboratory Accreditation Program - Procedures and General Requirements. James L. Cigler and Vanda R. White, eds. NVLAP Handbook 150, U.S. Department of Commerce, Technology Administration, Gaithersburg, Maryland.

National Institute of Standards and Technology (NIST). 1994. Guidelines for Evaluating and Expressing the Uncertainty of NIST Measurement Results. Barry N. Taylor and Chris E. Kuyatt, eds. Technical Note 1297, U.S. Department of Commerce, Technology Administration, Gaithersburg, Maryland.

U.S. Department of Commerce/National Institute of Standards and Technology. 1991. Criteria for the Operation of Federally Owned Secondary Calibration Laboratories (Ionizing Radiation). E.H. Eisenhower, ed. NIST Special Publication 812, Office of Standards Code and Information, U.S. Department of Commerce, Gaithersburg, Maryland.

U.S. Department of Energy. December 1986. Department of Energy Standard for the Performance Testing of Personnel Dosimetry Systems - DOE Laboratory Program for Personnel Dosimetry Systems. DOE/EH-0027.

\section{Further information:}

Mark Hevland - (509) 376-4014

Don Bihl - (509) 376-6819

Michelle Johnson - (509) 376-5624

$$
\begin{gathered}
\text { Tim Lynch - (509) 376-6281 } \\
\text { Mike Mercado - (509) 376-7316 } \\
\text { Kim Piper - (509) 376-6187 }
\end{gathered}
$$

$$
\begin{gathered}
\text { e-mail - calibration@pnl.gov } \\
\text { website - http://www.pnl.gov.eshs/ }
\end{gathered}
$$

